\title{
Credit and Firm-Level Volatility of
}

\section{Employment}

\author{
Vincenzo Quadrini* \\ University of Southern California \\ Qi $\operatorname{Sun}^{\dagger}$ \\ Shanghai University of Finance and Economics
}

\begin{abstract}
We study a firm dynamics model where access to credit improves the bargaining position of firms with workers and increases the incentive to hire. To evaluate the importance of the bargaining channel for the hiring decisions of firms, we estimate the model structurally using data from Compustat and Capital IQ. We find that the bargaining channel contributes to about $5.7 \%$ of variation in firm-level employment. We also evaluate the contribution of different types of firm-level shocks to employment volatility and find that credit shocks contribute to about $8 \%$, revenue shocks to $48 \%$ and job separation shocks to $44 \%$.
\end{abstract}

\footnotetext{
${ }^{*}$ Department of Finance and Business Economics, Marshall School of Business, University of Southern California, 701 Exposition Boulevard, Los Angeles, CA 90089. e-mail: quadrini@usc.edu

${ }^{\dagger}$ School of Finance, Shanghai University of Finance and Economics, 100 Wudong Road, Shanghai, China, 200433. e-mail: sunqi@mail.shufe.edu.cn
} 


\section{Introduction}

The idea that firms use leverage strategically to improve their bargaining position with workers is not new in the labor and corporate finance literature. For example, Bronars and Deere (1991), Dasgupta and Sengupta (1993) and Perotti and Spier (1993) developed models where debt reduces the bargaining surplus for the negotiation of wages, allowing firms to lower the cost of labor. Studies by Klasa et al. (2009) and Matsa (2010) have tested this mechanism using firm-level data and found that more unionized firms - that is, firms where workers are likely to have more bargaining power - are characterized by higher leverage and lower cash holdings. More recently, Ellul and Pagano (2015) showed that the choice of leverage depends on the seniority of employees claims in the liquidation of insolvent firms. Using an index of employees' protection in bankruptcy for different countries they find empirical support to the prediction of the model.

These studies provide empirical evidence that the bargaining power of workers is relevant for determining the financial structure of firms. However, whether this is also important for their hiring decisions has not been fully explored in the literature. In fact, if the bargaining strength of workers impacts on the financial structure of firms, the financial structure may in turn affect the hiring decision of firms. Specifically, if higher leverage allows employers to negotiate more favorable conditions with employees, the ability to issue more debt should increase the incentive to hire. We refer to this mechanism as the 'bargaining channel of debt'. The goal of this paper is to study the importance of this channel by developing and estimating a dynamic model with endogenous choices of employment and financial structure. ${ }^{1}$

In the model, the compensation of workers is determined at the firm level through bargaining. Firms choose the financial structure and employment optimally taking into account that these choices affect the cost of labor. Higher debt allows firms to negotiate lower wages

\footnotetext{
${ }^{1}$ Monacelli et al. (2011) studies the importance of the bargaining channel for aggregate dynamics in a model with a single-worker representative firm. In this paper, instead, we take a micro approach and explore the empirical relevance of this channel using a model with heterogeneous multi-worker firms that can be mapped to firm-level data. A similar approach is taken by Michaels et al. (2014).
} 
which increases the incentive to hire more workers. Higher debt, however, also increases the likelihood of financial distress. When the financial condition of a firm improves, the likelihood of financial distress declines, making debt more attractive. This improves the bargaining position of the firm with its employees, increasing the incentive to hire. It is through this mechanism that improved firm-level access to credit generates higher demand for labor.

We evaluate the importance of this channel by estimating the model with the simulated method of moments. The empirical moments are constructed using firm-level data from Compustat and Capital IQ. The first database provides information on typical balance sheet and operational variables including employment. The second database provides firm-level data for unused lines of credit which is important for the identification of some of the key parameters. More specifically, since the likelihood of financial distress increases with leverage, firms borrow less than the credit capacity (precautionary motive). As an empirical proxy for the difference between the credit capacity and the actual borrowing in the model, we use the data "unused lines of credit" from Capital IQ. This variable provides valuable information for the identification of the parameter that determines the cost of financial distress.

After the estimation of the model, we evaluate the importance of the bargaining channel for the dynamics of employment by conducting a counterfactual exercise in which debt does not affect the bargaining of wages. By comparing the simulation of this model to the simulation of the benchmark model we find that the bargaining channel contributes about 5.7\% to the overall volatility of firm-level employment.

In addition to the structural estimation, we also investigate the importance of the bargaining channel with reduced-form regressions. The regressions test the property of the model for which the sensitivity of employment to debt increases with the bargaining power of workers. To proxy for the bargaining power of workers we use the unionization index from the Union Membership and Coverage Database. We then regress the firm-level growth rate of employment on a set of variables that include the growth rate of debt, the unionization index and the interaction between debt growth and unionization (in addition to other controls). 
The main variable of interest is the interaction term between the growth rate of debt and the unionization index. We find that the estimated coefficient is positive and statistically significant, which is consistent with the theoretical prediction of the model.

The second goal of the paper is, more generally, to evaluate the importance of different types of firm-level shocks to employment fluctuation. We consider three types of firm-level shocks: credit shocks, revenue or productivity shocks, and job separation shocks. When we simulate the estimated model with only one shock (and imposing that the realizations of the other two shocks are equal to the unconditional means) we find that the contribution of credit shocks is about $8 \%$, the contribution of revenue shocks is about $48 \%$, and the contribution of job separation shocks is about $44 \%$.

The remaining sections of the paper are organized as follows. Sections 1 and 2 present the dynamic model and characterize some of its properties. Section 3 describes the data, the structural estimation and reports the results. Section 5 conducts the empirical analysis based on reduced-form regressions. Section 6 concludes.

\section{A firm dynamics model with wage bargaining}

To illustrate the role played by the bargaining channel of debt, we first present a simplified version of the model without financial distress. The model will then be extended by adding the cost of financial distress.

Consider a firm with production technology $y_{t}=z_{t} N_{t}$, where $z_{t}$ is idiosyncratic productivity and $N_{t}$ is the number of workers. Employment evolves according to

$$
N_{t+1}=(1-\lambda) N_{t}+H_{t}
$$

where $\lambda$ is the separation rate and $H_{t}$ denotes the newly hired workers.

Hiring is costly. A firm with current employment $N_{t}$ that hires $H_{t}$ workers incurs the cost $\Upsilon\left(\frac{H_{t}}{N_{t}}\right) N_{t}$, where the function $\Upsilon(\cdot)$ is strictly increasing and convex. 
The budget constraint of the firm is

$$
B_{t}+D_{t}+w_{t} N_{t}+\Upsilon\left(\frac{H_{t}}{N_{t}}\right) N_{t}=z_{t} N_{t}+q_{t} B_{t+1}
$$

where $B_{t}$ is the debt issued at $t-1, D_{t}$ is the equity payout, $w_{t}$ is the wage paid to each worker and $q_{t}$ is the price of new bonds.

The impact of taxes on the optimal choice of debt is implicitly captured by the price of new bonds $q_{t}$. Denoting by $\tau_{t}$ the corporate tax rate and by $r_{t}$ the interest rate, the 'effective' interest rate is $\left(1-\tau_{t}\right) r_{t}$ and the 'effective' price of debt is $q_{t}=\frac{1}{1+\left(1-\tau_{t}\right) r_{t}} \cdot{ }^{2}$ We will distinguish the interest rate $r_{t}$ from the tax rate $\tau_{t}$ when we conduct the quantitative exercise. For the theoretical analysis we can simply focus on the effective price of debt $q_{t}$.

The issuance of debt is subject to the enforcement constraint

$$
q_{t} B_{t+1} \leq \xi_{t} \beta \mathbb{E}_{t} S_{t+1},
$$

where $\beta$ is the discount factor of investors and $S_{t+1}$ is the net surplus of the firm as defined below. The variable $\xi_{t}$ is stochastic and captures the financial conditions of the firm, that is, its access to external credit.

We specify the enforcement constraint as a fraction of the whole surplus, which includes the part going to workers. An alternative would be to assume that the constraint depends only on the value of the firm for the equity holders. Since the equity holders will get a fraction of the surplus (as we will see shortly), this alternative specification would be exactly equivalent to the one used here after normalizing $\xi_{t}$ by the bargaining share.

\footnotetext{
${ }^{2}$ The typical approach in modeling the fiscal benefits of debt is to tax the net corporate income after the interest payments (e.g., Hennessy and Whited (2005) and Li et al. (2014)). An alternate approach is to calculate the effective interest rate after considering the tax shield (e.g., Jermann and Quadrini (2012)). We use this second approach because it allows for simpler notation without changing the properties of the model.
} 


\subsection{Firm's policies and wages}

The policies of the firm, including wages, are bargained collectively with its labor force. The labor force is defined broadly including managers. In this way the model also captures the potential conflicts between shareholders and managers as in Jensen (1986).

To derive the bargaining outcome, it will be convenient to define few terms starting with the equity value of the firm. This can be written recursively as

$$
V_{t}\left(B_{t}, N_{t}\right)=D_{t}+\beta \mathbb{E}_{t} V_{t+1}\left(B_{t+1}, N_{t+1}\right) .
$$

The equity value of the firm depends on two endogenous states, debt $B_{t}$ and employment $N_{t}$, in addition to the exogenous states $z_{t}$ and $\xi_{t}$. To simplify the notation, the dependence on the exogenous states is not shown explicitly but it is captured by the time subscript $t$. We will continue to use this notational convention throughout the paper.

The value of a worker employed in a firm with liabilities $B_{t}$ and with $N_{t}$ employees is

$$
W_{t}\left(B_{t}, N_{t}\right)=w_{t}+\beta \mathbb{E}_{t}\left[\lambda U_{t+1}+(1-\lambda) W_{t+1}\left(B_{t+1}, N_{t+1}\right)\right],
$$

where $U_{t+1}$ is the value of being unemployed at $t+1$. Given the partial equilibrium approach, the value of being unemployed is exogenous in the model.

The value for the worker, $W_{t}\left(B_{t}, N_{t}\right)$, net of the outside value, $U_{t}$, can be rewritten recursively as

$$
W_{t}\left(B_{t}, N_{t}\right)-U_{t}=w_{t}-U_{t}+\beta \mathbb{E}_{t}\left[U_{t+1}+(1-\lambda)\left(W_{t+1}\left(B_{t+1}, N_{t+1}\right)-U_{t+1}\right)\right]
$$

Equation (6) is derived by subtracting $U_{t}$ on the both side of equation (5) and rearranging the terms in the parentheses. 
The bargaining surplus is the sum of the net values for the firm and the workers, that is,

$$
S_{t}\left(B_{t}, N_{t}\right)=V_{t}\left(B_{t}, N_{t}\right)+\left(W_{t}\left(B_{t}, N_{t}\right)-U_{t}\right) N_{t}
$$

We are now ready to define the bargaining problem. Given $\eta$ the bargaining power of workers, the bargaining problem can be written as

$$
\max _{w_{t}, D_{t}, E_{t}, B_{t+1}} \quad\left[\left(W_{t}\left(B_{t}, N_{t}\right)-U_{t}\right) N_{t}\right]^{\eta} \cdot V_{t}\left(B_{t}, N_{t}\right)^{1-\eta}
$$

subject to the law of motion for employment (1), the budget constraint (2), and the enforcement constraint (3).

Differentiating with respect to the wage $w_{t}$, we obtain the well-known result that workers receive a fraction $\eta$ of the bargaining surplus while the firm receives the remaining fraction,

$$
\begin{aligned}
\left(W_{t}\left(B_{t}, N_{t}\right)-U_{t}\right) N_{t} & =\eta S_{t}\left(B_{t}, N_{t}\right) \\
V_{t}\left(B_{t}, N_{t}\right) & =(1-\eta) S_{t}\left(B_{t}, N_{t}\right) .
\end{aligned}
$$

Next we derive the first order conditions with respect to $D_{t}, H_{t}, B_{t+1}$. Using (8) and (9), we find that dividend, employment, and financial policies simply maximize the net surplus $S_{t}\left(B_{t}, N_{t}\right)$. This property is intuitive: given that the contractual parties (firm and workers) share the net bargaining surplus, it is in the interest of both parties to make the surplus as big as possible. Therefore, in characterizing the hiring and financial policies of the firm we focus on the maximization of the net surplus which, in recursive form, can be written as

$$
S_{t}\left(B_{t}, N_{t}\right)=\max _{H_{t}, B_{t+1}}\left\{D_{t}+\left(w_{t}-u_{t}\right) N_{t}+\beta\left[1-\eta+\eta(1-\lambda)\left(\frac{N_{t}}{N_{t+1}}\right)\right] \mathbb{E}_{t} S_{t+1}\left(B_{t+1}, N_{t+1}\right)\right\}
$$

subject to $(1),(2),(3)$. 
The recursive formulation is obtained by multiplying equation (6) by $N_{t}$, summing to (4), and using the sharing rules (8) and (9). The term $u_{t}=U_{t}-\beta \mathbb{E}_{t} U_{t+1}$ is exogenous, given that the analysis is limited to a partial equilibrium.

We now take advantage of the linearity of the model and express all variables in per-worker terms. Normalizing by $N_{t}$, the optimization problem can be rewritten as

$$
s_{t}\left(b_{t}\right)=\max _{h_{t}, b_{t+1}}\left\{d_{t}+w_{t}-u_{t}+\beta\left(g_{t+1}-\eta h_{t}\right) \mathbb{E}_{t} s_{t+1}\left(b_{t+1}\right)\right\}
$$

subject to:

$$
\begin{aligned}
& d_{t}+w_{t}=z_{t}-\Upsilon\left(h_{t}\right)+q_{t} g_{t+1} b_{t+1}-b_{t} \\
& \xi_{t} g_{t+1} \beta \mathbb{E}_{t} s_{t+1}\left(b_{t+1}\right) \geq q_{t} g_{t+1} b_{t+1} \\
& g_{t+1}=1-\lambda+h_{t} .
\end{aligned}
$$

The variable $s_{t}\left(b_{t}\right)=S_{t}\left(b_{t}\right) / N_{t}$ is the per-worker surplus, $d_{t}=d_{t} / N_{t}$ is the per-worker dividend paid to shareholders, $b_{t}=B_{t} / N_{t}$ is the per-worker liabilities, $h_{t}=H_{t} / N_{t}$ denotes the newly hired workers per existing employees, and $g_{t+1}=N_{t+1} / N_{t}$ is the gross growth rate of employment.

Of special interest is the discount factor for the next period's normalized surplus, $\beta\left(g_{t+1}-\right.$ $\left.\eta h_{t}\right)$. When workers have zero bargaining power, that is, $\eta=0$, the discount factor reduces to $\beta g_{t+1}$. Since the whole surplus goes to shareholders, they will also get the whole next period's surplus. When $\eta>0$, however, some of the next period's surplus needs to be shared with the new hired workers. This is captured by the reduction in the discount factor by the term $\eta h_{t}$. Of course, the 'lower discounting' is relevant only if firms add new workers in the next period, that is, when $h_{t}>0$. Therefore, the main conflict in the choice of the firm's policies is not between shareholders and existing employees but between current stake holders (shareholders and existing employees) and new workers.

To characterize the hiring and financial policies of the firm, we derive the first order condi- 
tions with respect to $h_{t}$ and $b_{t+1}$. Denoting by $\mu_{t}$ the lagrange multiplier for the enforcement constraint, the first order conditions read

$$
\begin{aligned}
& q_{t} b_{t+1}+\beta(1-\eta) \mathbb{E}_{t} s_{t+1}\left(b_{t+1}\right)=\Upsilon^{\prime}\left(h_{t}\right) \\
& q_{t} g_{t+1}+\beta\left(q_{t+1}-\eta h_{t}\right) \mathbb{E}_{t} \frac{\partial s_{t+1}\left(b_{t+1}\right)}{\partial b_{t+1}}+\mu_{t} g_{t+1}\left[\xi_{t} \beta \mathbb{E}_{t} \frac{\partial s_{t+1}\left(b_{t+1}\right)}{\partial b_{t+1}}-q_{t}\right]=0
\end{aligned}
$$

The envelope condition provides the derivative of the surplus, which is equal to $\partial s_{t}\left(b_{t}\right) / \partial b_{t}=$ -1 . The linearity allows us to rewrite the surplus as

$$
s_{t}\left(b_{t}\right)=\bar{s}_{t}-b_{t}
$$

where $\bar{s}_{t}$ depends only on the exogenous states (shocks). The first order conditions can then be rewritten as

$$
\begin{aligned}
& q_{t} b_{t+1}+\beta(1-\eta)\left(\mathbb{E}_{t} \bar{s}_{t+1}-b_{t+1}\right)=\Upsilon^{\prime}\left(h_{t}\right), \\
& q_{t} g_{t+1}=\beta\left(g_{t+1}-\eta h_{t}\right)+\mu_{t} g_{t+1}\left(\beta \xi_{t}+q_{t}\right) .
\end{aligned}
$$

\subsection{Special case with $q_{t}=\beta$}

Since we are focusing on a partial equilibrium and we abstract from aggregate shocks, it makes sense to assume that the interest rate is constant and equal to the intertemporal discount rate, that is, $r_{t}=1 / \beta-1$. Furthermore, if we abstract from taxes $\left(\tau_{t}=0\right)$, the effective price of bonds is $q_{t}=\beta$. The following proposition establishes some properties for the financial policy of the firm for this special case.

Proposition 1.1 Suppose that $q_{t}=\beta$. If $\eta>0$, the firm borrows up to the limit whenever $h_{t}>0$. If $\eta=0$ or $h_{t}=0$, the debt is undetermined.

Proof 1.1 When $q_{t}=\beta$, the first order condition for debt, equation (13), simplifies to $\eta h_{t}=\mu_{t} g_{t+1}\left(1+\xi_{t}\right)$. If $\eta>0$, the equation implies that the lagrange multiplier $\mu_{t}$ is strictly 
positive whenever $h_{t}>0$. Therefore, under the condition $h_{t}>0$ the enforcement constraint is binding. When $\eta=0$ or $h_{t}=0$, the equation implies that $\mu_{t}$ is zero. Therefore, the enforcement constraint is not binding and debt is undetermined.

There is a simple intuition for this property. Whenever the firm chooses to hire, that is, $h_{t}>0$, it adds new workers who will become part of the firm's employment starting in the next period. The new workers will share the next period's surplus. Increasing the debt today reduces the future surplus and allows for lower compensation of the new hired workers. This increases the current surplus of the firm which is shared by shareholders and currently employed workers, but not the new hired workers. It is then in the interest of both shareholders and existing employees to increase the debt of the firm. When the firm does not add new workers, however, higher borrowing does not increase the current surplus because more debt only reduces the future compensation of existing workers. In this case there are no gains from borrowing. Thus, as long as the firm adds new workers, bargaining introduces a motive to borrow, breaking the irrelevance of the financial structure as in Modigliani and Miller (1958). This applies only if the bargaining power of workers is positive, that is, $\eta>0$.

We now turn attention to the optimal hiring policy which is characterized by the first order condition (12). Together with the normalized law of motion for employment, $g_{t+1}=1-\lambda+h_{t}$, this equation establishes a relation between the per-worker debt $b_{t+1}$ and the growth of employment (which also depends on other factors affecting the surplus of the firm through the term $\left.\mathbb{E}_{t} \bar{s}_{t+1}\right)$. This relation is not linear and depends on the bargaining power of workers $\eta$. The next proposition characterizes some properties of the hiring policy under the special case in which $q_{t}=\beta$.

Proposition 1.2 Suppose that $q_{t}=\beta$. The hiring decision $h_{t}$ is strictly increasing in $b_{t+1}$ if $\eta>0$ but it is independent of $b_{t+1}$ if $\eta=0$.

Proof 1.2 When $q_{t}=\beta$, the first order condition (12) can be rewritten as

$$
\beta\left[\eta b_{t+1}+(1-\eta) \mathbb{E}_{t} \bar{s}_{t+1}\right]=\Upsilon^{\prime}\left(h_{t}\right) .
$$


Given the convexity of the hiring cost, $\Upsilon^{\prime}\left(h_{t}\right)$ is strictly increasing in $h_{t}$. Since the term $\mathbb{E}_{t} \bar{s}_{t+1}$ depends only on the exogenous shocks, $h_{t}$ is strictly increasing in $b_{t+1}$ whenever $\eta>0$. When $\eta=0$ the above equation implies that $h_{t}$ is independent of $b_{t+1}$.

Therefore, the financial structure of the firm affects hiring as long as workers have some bargaining power. When workers have zero bargaining power-which can be interpreted as the case of a competitive labor market where the determination of wages is external to an individual firm - debt is irrelevant for the hiring decision of firms.

The above propositions can be easily extended to the more general case in which $q_{t}>\beta$. For example, if $r_{t}=1 / \beta-1$ and the corporate tax rate is positive. In this case the firm has an additional motive to borrow (since the effective cost of debt is lower than the cost of equity). This implies that the debt is no longer undetermined when $\eta=0$ or $h_{t}=0$ (Proposition 1.1). Furthermore, the hiring policy of the firm is no longer independent of the debt even if $\eta=0$ (Proposition 1.2). However, it is still the case that the bargaining power of workers $\eta$ increases the sensitivity of $h_{t}$ to $b_{t+1}$.

\section{Financial distress cost}

The model presented so far abstracts from the possibility that higher debt increases the probability of financial distress. As a result, firms always borrow up to the limit (at least when they hires new workers).

The borrowing limit is determined by the variable $\xi_{t}$ which changes stochastically in the model. A sudden drop in this variable forces the firm to substitute debt with equity and this can be done without any direct cost. The only cost is indirect, through the impact on wages. However, the assumption that there is full flexibility in substituting debt with equity is not plausible, especially in the short-run: if the firm is unexpectedly forced to replace debt with equity, it might incur some cost. To capture this idea, we now extend the model to allow for the possibility of financial distress costs. 
Define $b_{t}^{*}$ the maximum debt that can be collateralized. This is defined by the condition $b_{t}^{*}=\xi_{t} s_{t}\left(b_{t}^{*}\right)$. Since the surplus function $s_{t}($.$) is strictly decreasing, the maximum debt b_{t}^{*}$ is increasing in $\xi_{t}$.

The firm enters the period with debt $b_{t}$ chosen in the previous period. Then, after the realization of $\xi_{t}$, the collateral constraint might no longer be satisfied, that is, $b_{t}>b_{t}^{*}=$ $\xi_{t} s_{t}\left(b_{t}^{*}\right)$. In this case the firm will be forced to pay back the difference $b_{t}-b_{t}^{*}$ before it can access the equity market or retain earnings. In order to make the payment, the firm needs to raise $b_{t}-b_{t}^{*}$ with alternative sources that are costly. In particular, we assume that the cost incurred to access these alternative sources of funds is $\kappa\left(b_{t}-b_{t}^{*}\right)^{2}$. We call this cost 'financial distress cost' since it is paid to raise emergency funds and could also include, in the extreme, the cost of bankruptcy. The cost can be expressed more generally as $\varphi_{t}\left(b_{t}\right)=\kappa \cdot \max \left\{b_{t}-b_{t}^{*}, 0\right\}^{2}$.

With financial distress, the normalized problem of the firm becomes

$$
s_{t}\left(b_{t}\right)=\max _{h_{t}, b_{t+1}}\left\{d_{t}+w_{t}-u_{t}+\beta\left(g_{t+1}-\eta h_{t}\right) \mathbb{E}_{t} s_{t+1}\left(b_{t+1}\right)\right\}
$$

subject to:

$$
\begin{aligned}
& d_{t}+w_{t}=z_{t}-\Upsilon\left(h_{t}\right)+q_{t} g_{t+1} b_{t+1}-b_{t}-\varphi_{t}\left(b_{t}\right) \\
& \xi_{t} g_{t+1} \beta \mathbb{E}_{t} s_{t+1}\left(b_{t+1}\right) \geq q_{t} g_{t+1} b_{t+1} \\
& g_{t+1}=1-\lambda+h_{t} .
\end{aligned}
$$

This problem is similar to the previous problem (10). The only difference is that the budget constraint also includes the distress $\operatorname{cost} \varphi_{t}\left(b_{t}\right)$. Notice that the surplus function $s_{t}\left(b_{t}\right)$ is net of the distress cost. If $\varphi_{t}\left(b_{t}\right)=0$ for all $b_{t}$, we go back to the previous problem. Although this may seem a minor modification, it has important implications for the optimal decisions of firms since it generates a precautionary motive in the choice of $b_{t+1}$. As a result, the borrowing constraint will be binding only occasionally. This feature of the model is 
similar to Boileau and Moyen (2009) where firms may hold cash for precautionary reasons.

\subsection{Optimal policies with financial distress}

To characterize the hiring and financial policies of the firm, we derive the first order conditions from problem (14) by differentiating with respect to $h_{t}$ and $b_{t+1}$, respectively. The resulting conditions are

$$
\begin{aligned}
& q_{t} b_{t+1}+\beta(1-\eta) \mathbb{E}_{t} s_{t+1}\left(b_{t+1}\right)=\Upsilon^{\prime}\left(h_{t}\right) \\
& q_{t} g_{t+1}+\beta\left(g_{t+1}-\eta h_{t}\right) \mathbb{E}_{t} \frac{\partial s_{t+1}\left(b_{t+1}\right)}{\partial b_{t+1}}+\mu_{t} g_{t+1}\left[\beta \xi_{t} \mathbb{E}_{t} \frac{\partial s_{t+1}\left(b_{t+1}\right)}{\partial b_{t+1}}-q_{t}\right]=0
\end{aligned}
$$

where $\mu_{t}$ is the lagrange multiplier for the enforcement constraint. These conditions do not depend on $b_{t}$. Therefore, the optimal employment and new debt are still independent of current liabilities.

The envelope condition returns $\partial s_{t}\left(b_{t}\right) / \partial b_{t}=-1-\varphi_{t}^{\prime}\left(b_{t}\right)$, which allows us to write the surplus function, net of the distress cost, as

$$
s_{t}\left(b_{t}\right)=\bar{s}_{t}-b_{t}-\varphi_{t}\left(b_{t}\right)
$$

As in the model without financial distress, the variable $\bar{s}_{t}$ depends only on the exogenous shocks. The surplus function, however, is no longer linear in $b_{t}$. The convexity of the distress cost makes the surplus function concave, introducing a precautionary motive that discourages borrowing. Thus, the firm may choose not to borrow up to the limit and the borrowing constraint could be only occasionally binding, that is, $\xi_{t} g_{t+1} \beta \mathbb{E}_{t} s_{t+1}\left(b_{t+1}\right) \geq q_{t} g_{t+1} b_{t+1}$.

Figure 1 provides a graphical illustration of the optimal choice of debt. The first panel depicts the model without financial distress. In this case the marginal benefit of debt is always bigger than the marginal cost of borrowing (provided that the firm chooses positive hiring and $\eta>0$ ). This is because the marginal benefit of debt also includes the reduced future cost of labor made possible by a marginal increase in debt. Therefore, the firm always 
borrows up to the limit, which is indicated in the graph by the vertical line.

The case with financial distress is depicted in the second panel of Figure 1. In this case the marginal cost is initially below the marginal benefit. However, as the debt increases, the expected cost of financial distress rises, inducing an increase in the marginal cost of debt. As a result, the firm does not borrow up to the limit. Furthermore, the difference between the borrowing limit and the actual debt increases with the financial distress cost captured by the parameter $\kappa$.

MODEL WITHOUT FINANCIAL DISTRESS

MODEL WITH FINANCIAL DISTRESS
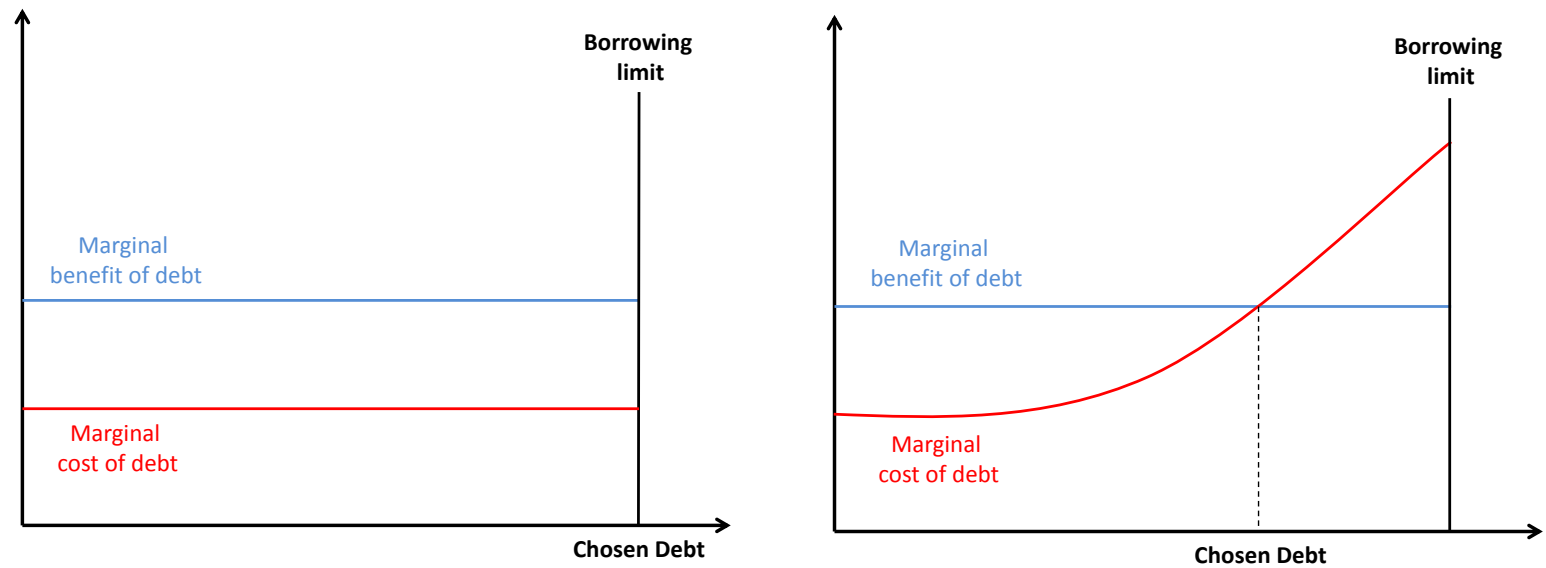

Figure 1: Optimal debt policy.

\subsection{Reformulation of the optimization problem}

We can now use the special form of the surplus function to derive expressions for the maximum collateralizable debt. First we use the condition that determines the maximum collateralizable debt, that is, $b_{t}^{*}=\xi_{t} s_{t}\left(b_{t}^{*}\right)$. Using (17) to eliminating $s_{t}\left(b_{t}^{*}\right)$, we obtain $b_{t}^{*}=\xi_{t}\left[\bar{s}_{t}-b_{t}^{*}-\varphi_{t}\left(b_{t}^{*}\right)\right]$. Since $\varphi\left(b_{t}^{*}\right)=0$ by definition, we can solve the last equation for $b_{t}^{*}$, that is,

$$
b_{t}^{*}=\left(\frac{\xi_{t}}{1+\xi_{t}}\right) \bar{s}_{t} .
$$

Therefore, the maximum collateralizable debt is only determined by the exogenous states, $z_{t}$ and $\xi_{t}$. Finally, the particular form of the surplus function derived in (17) allows us to 
write the firm's problem as

$$
\bar{s}_{t}=\max _{h_{t}, b_{t+1}}\left\{z_{t}-\Upsilon\left(h_{t}\right)+q_{t} g_{t+1} b_{t+1}-u_{t}+\beta\left(g_{t+1}-\eta h_{t}\right) \mathbb{E}_{t}\left[\bar{s}_{t+1}-b_{t+1}-\varphi_{t+1}\left(b_{t+1}\right)\right]\right\}
$$

subject to:

$$
\begin{aligned}
& \xi_{t} g_{t+1} \beta \mathbb{E}_{t}\left[\bar{s}_{t+1}-b_{t+1}-\varphi_{t+1}\left(b_{t+1}\right)\right] \geq q_{t} g_{t+1} b_{t+1} \\
& g_{t+1}=1-\lambda+h_{t} .
\end{aligned}
$$

This problem is recursive in $\bar{s}_{t}$, which depends only on the exogenous shocks. Therefore, to solve for the optimal policies we do not need to keep track of the endogenous state $b_{t}$, a property that simplifies the computational procedure as we will describe below.

Using the particular form of the surplus function, the first order conditions (15) and (16) can be rewritten as

$$
\begin{aligned}
& q_{t} b_{t+1}+\beta(1-\eta) \mathbb{E}_{t}\left[\bar{s}_{t+1}-b_{t+1}-\varphi_{t+1}\left(b_{t+1}\right)\right]=\Upsilon^{\prime}\left(h_{t}\right) \\
& q_{t} g_{t+1}=\beta\left(g_{t+1}-\eta h_{t}\right)\left(1+\mathbb{E}_{t} \varphi_{t+1}^{\prime}\left(b_{t+1}\right)\right)+\mu_{t} g_{t+1}\left[\beta \xi_{t}\left(1+\mathbb{E}_{t} \varphi_{t+1}^{\prime}\left(b_{t+1}\right)\right)+q_{t}\right]
\end{aligned}
$$

Some of the properties stated in Propositions 1.1 and 1.2 also apply to the model with financial distress. In particular, if workers do not have any bargaining power $(\eta=0)$ and $q_{t}=\beta$, we can see from equation (21) that the enforcement constraint is never binding $\left(\mu_{t}=0\right)$ and the expected distress cost is zero $\left(\mathbb{E}_{t} \varphi_{t+1}\left(b_{t+1}\right)=0\right)$.

Since debt does not provide any value when $\eta=0$, the firm does not borrow to avoid the distress cost. At the same time, since the firm does not borrow and the expected distress cost is zero, the hiring decision characterized by condition (20) is not affected by the financial condition of the firm, the variable $\xi_{t}$. 


\subsection{Computation of the optimal policies}

The solution to the normalized problem consists of functions for the hiring policy, $e_{t}$, for the borrowing policy, $b_{t+1}$, and for the surplus variable $\bar{s}_{t}$. These variables do not depend on the endogenous state $b_{t}$ but only on the exogenous shocks $z_{t}$ and $\xi_{t}$. If the shocks take a finite number of values, $\bar{s}_{t}$ also takes a finite number of values. Therefore, problem (19) is a Bellman's equation in the unknown vector $\overline{\mathbf{s}}$. This vector contains the values of $\bar{s}_{t}$ associated with all (finite) realizations of the two shocks. The solution is found by iterating on the Bellman equation until we find a fixed point $\overline{\mathbf{s}}$.

Denote by $n_{z}$ and $n_{\xi}$ the number of possible values for productivity and financial shocks. Each iteration starts with a guess for the vector $\overline{\mathbf{s}}_{t+1}$, that is, the vector that contains the $n_{z} \times n_{\xi}$ elements of the surplus $\bar{s}_{t+1}$ in the next period. For each combination of the two shocks in the current period and given the guess for the vector $\overline{\mathbf{s}}_{t+1}$, we derive the optimal policies by solving the first order conditions (20) and (21) together with the enforcement constraint in problem (19). Since the enforcement constraint could be satisfied with equality (in which case $\mu_{t}>0$ ) or with inequality (in which case $\mu_{t}=0$ ), we have to verify the Kuhn-Tucker conditions for interior or binding solutions. The policy rules for employment and borrowing allow us to determine $\bar{s}_{t}$ for each combination of the two shocks. The computed vector $\overline{\mathbf{s}}_{t}$ is then used as a new guess for $\overline{\mathbf{s}}_{t+1}$. Notice that, as long as the exogenous shocks take a finite number of values, the solution is not an approximation.

\section{Structural estimation}

To make the model more suitable for the empirical application, we add a third shock to the model. In particular we assume that the separation rate $\lambda$ is stochastic. This captures the idea that labor retention is likely to be uncertain at the firm level. It also captures uncertainty in hiring since in the model a shock to job creation is isomorphic to a shock that affects job separation. 
Employment continues to evolve according to $N_{t+1}=\left(1-\lambda_{t}\right) N_{t}+H_{t}$, but $\lambda_{t}$ is stochastic and follows a first order Markov process at the firm level (idiosyncratic). The problem takes the same form as in (19) but with three firm-level shocks: productivity, $z_{t}$, credit, $\xi_{t}$, and separation, $\lambda_{t}$. The first order conditions are also similar and the previous analysis applies to the model with stochastic separation.

\subsection{Data}

With the exception of unused lines of credit, all variables are from COMPUSTAT Annual. Data on unused lines of credit are not available in COMPUSTAT and some studies collect information about credit lines from firms' SEC 10-K files (see, for example, Sufi (2009)). We use data from Capital IQ database which contains a large sample of unused lines of credit from 2003 to 2010. The variable unused lines of credit also refers to total undrawn credit. For a more detailed description see Ippolito and Pérez Orive (2012). Capital IQ data on unused lines of credit has also be used by Gilchrist and Zakrajsek (2012) to study the macroeconomic impact of credit supply shocks.

Following the literature, we exclude utilities and financial firms with SIC codes in the intervals 4900-4949 and 6000-6999, and firms with SIC codes greater than 9000. We also exclude firms with missing values of assets, sales, number of employees, debt, and unused lines of credit during the sample period. Since we need to calculate empirical moments that require repeated observations for each individual firm (such as standard deviations and autocorrelations), we drop firms with less than 3 years of data. To limit the impact of outliers (e.g., merges and acquisitions), we also winsorize all level variables at $2.5 \%$ and $97.5 \%$ percentiles, and growth variables at $5 \%$ and $95 \%$ percentiles. Nominal variables are deflated by the Consumer Price Index. The final sample used in the structural estimation is an unbalanced panel (for each variable) of 2,528 firms over 8 years, from 2003 to $2010 .^{3}$ Appendix A provides the detailed definition of the variables used in the estimation.

\footnotetext{
${ }^{3}$ For robustness we also estimated the model using a balanced panel and obtained similar results.
} 


\subsection{Parameters and moments}

We need first to specify the functional form for the hiring cost function. This is assumed to take the quadratic form $\Upsilon\left(h_{t}\right)=\phi h_{t}+\zeta h_{t}^{2}$, where $\phi$ and $\zeta$ are parameters and $h_{t}=\frac{H_{t}}{N_{t}}$ is the ratio of new hires over current employment. The three shocks $\left(z_{t}, \xi_{t}, \lambda_{t}\right)$ follow independent first order Markov processes approximated with discrete Markov chains with each variable taking 5 possible values.

The estimation procedure is based on the simulated method of moments as in Lee and Ingram (1991) (see Appendix B for a detailed description). All model parameters are estimated with the exception of the intertemporal discount factor, $\beta$, the corporate tax rate $\tau$, the average productivity $\bar{z}$, the hiring cost parameter $\zeta$, and the average enforcement $\bar{\xi}$.

The discount factor $\beta$ is set to 0.97 , which implies an interest rate close to 3 percent. The corporate tax rate (which affects the effective cost of borrowing) is set $\tau=0.2$. We will later check the sensitivity of the results to this parameter. The average productivity $\bar{z}$ is normalized to 1 . The hiring parameter $\zeta$ is chosen so that in the steady state the growth rate of the firm is zero (given all other parameters). This condition is a normalization insuring the stationarity of the model, that is, there is no unconditional growth. The value of $\bar{\xi}$ is chosen so that in the steady state the credit-to-surplus ratio in the model equals the creditto-equity ratio in the data. As a robustness check, we also estimate the model for alternative calibration of $\bar{\xi}$.

We are then left with 11 parameters: the persistence and volatility of the productivity shock, $\rho_{z}$ and $\sigma_{z}$, the persistence and volatility of credit shock, $\rho_{\xi}$ and $\sigma_{\xi}$, the persistence and volatility of separation shock, $\rho_{\lambda}$ and $\sigma_{\lambda}$, the financial distress cost, $\kappa$, the workers' bargaining power, $\eta$, the hiring cost, $\phi$, the average separation, $\bar{\lambda}$, the unemployment flow, $\bar{u}$ (which we impose to be constant since there are no aggregate shocks in the model).

To estimate these parameters we consider 15 empirical moments that have clear counterparts in the model: the mean of the ratio of unused credit over total credit ( 1 moment); the standard deviations and autocorrelations of the ratio of unused credit over total credit, em- 
ployment growth, sales growth, and total credit growth (8 moments); the cross correlations of the ratio of unused credit over total credit, employment growth, sales growth, and total credit growth (6 moments).

\subsubsection{Identification}

The values of the estimated parameters are reported in the bottom section of Table 1. Before commenting on the economic significance of the estimates, however, it is important to describe the identification mechanisms. We do so by conducting a sensitivity analysis with results reported in Table 2. The first column of this table reports the moments generated by the simulation of the model under the estimated parameters (benchmark parametrization as reported in Table 1). The remaining columns show the simulated moments after increasing by $15 \%$ the value of one particular parameter (keeping the values of all other parameters at the benchmark parametrization).

The parameters of the productivity shock (persistence $\rho_{z}$ and volatility $\sigma_{z}$ ) are mainly identified by the standard deviation and autocorrelation of sale growth, although the productivity shock also affects the level of unused credit ratio. The parameters of the credit shock (persistence $\rho_{\xi}$ and volatility $\sigma_{\xi}$ ) are mainly identified by the standard deviation and autocorrelation of credit growth. The parameters of the separation shock (persistence $\rho_{\lambda}$ and volatility $\sigma_{\lambda}$ ) are mainly identified by the standard deviation and autocorrelation of employment growth.

The hiring cost function $\Upsilon\left(e_{t}\right)=\phi e_{t}+\zeta e_{t}^{2}$ is characterized by two parameters. However, we cannot identify them separately. Thus, as stated earlier, we normalize the value of $\zeta$, given the estimated value of $\phi$, so that the unconditional growth of firms is zero. The parameter $\phi$ is mainly identified by the correlation between employment growth and sale growth. Intuitively, $\phi$ affects the sensitivity of hiring with respect to revenues.

Employment growth plays an important role in the identification of the average separa-

tion rate $\bar{\lambda}$. A high separation rate means that more workers will be replaced every year 
(higher employment turnover). Thus, both the standard deviation and autocorrelation of employment growth help to identify the separation parameter $\bar{\lambda}$.

The size of unemployment flow $\bar{u}$ affects the total surplus, and therefore, the collateral value of the firm. An increase in $\bar{u}$ reduces the firm's credit capacity and raises the unused credit ratio. Also, as shown in the last column of Table 2, the volatility of unused credit ratio also increases with the unemployment flow $\bar{u}$. Thus, both the mean and standard deviation of the unused credit ratio contribute to the identification of the unemployment flow $\bar{u}$.

We now discuss the identification of the two parameters that are central to the main question addressed in the paper: the worker's bargaining power $\eta$ and the financial distress cost $\kappa$. To have a clear picture of the sensitivity of the model to these two parameters, Figure 3 shows how the moments generated by the model change as a function of the workers's bargaining share $\eta$. The moment reported in the figure are the 15 moments used in the estimation. Figure 4 reports the sensitivity of the same moments to the financial distress parameter $\kappa$.

As shown in Figure 3, almost all the moments contribute to the identification the bargaining parameter $\eta$. However, there are three moments that are especially important: the mean of unused credit ratio, the autocorrelation of employment growth, and the correlation between employment growth and credit growth. When the workers' bargaining share increases, the firm has higher incentive to borrow. As a result, the unused credit ratio decreases. Furthermore, due to the increase in the workers' bargaining share, the sensitivity of hiring to credit increases, and therefore, the correlation between employment growth and credit growth also increases. Most importantly, the importance of the bargaining channel of debt increases with the value of the bargaining share $\eta$. A stronger bargaining channel of debt increases the persistence of employment growth, as we will discuss in next section.

Figure 4 plots the moment sensitivity to the distress cost parameter $\kappa$. As discussed in Section 2, because of the financial distress costs, firms do not use all of their credit capacity. Furthermore, unused credit increases when the potential distress cost rises. This implies that 
the unused credit ratio plays an important role in pinning down the parameter $\kappa$. At the same time, given the quadratic form of the financial distress cost, increases in the parameter $\kappa$ would also reduce the volatility of credit growth and the volatility of the unused credit ratio. Thus, the level and volatility of the unused credit ratio play an important role in the identification of $\kappa$.

We conclude this section by pointing out that the number of moments used in the estimation is larger than the number of parameters. Thus, there is not a one-to-one mapping between the estimated parameters and the moments used in the estimation. All the parameters are jointly identified and the sensitivity exercise provides only an intuition for the identification mechanisms.

\subsection{Estimation results}

The values of the estimated parameters are reported in the bottom section of Table 1 . The estimation assigns a sizable bargaining power to workers $(\eta=0.384)$. This is important for the bargaining channel to be relevant. Another parameter that is important for this channel is the average separation $\bar{\lambda}$, which is estimated to be 0.396 . A high separation rate implies high turnover rates and, therefore, high rates of hiring. High rates of hiring increase the importance of the bargaining channel of debt because, as we have seen in the theoretical section, higher debt allows for lower compensation of new workers. We also observe that credit and productivity shocks are quite persistent while the separation shocks are not persistent.

The values of the moments (observed and simulated) are reported in the top section of Table 1. The model does a reasonable job in replicating the 15 moments used in the estimation. One moment for which there is a sizable divergence between the empirical and simulated moments is the autocorrelation of employment growth. In the data the autocorrelation is close to zero. The model, however, generates a positive autocorrelation of 0.179 . This is a consequence of the particular structure of the model where the level of debt affects the growth of employment. As a result, a persistent increase in the debt level induces, through 
the bargaining channel, a persistent increase in the growth rate of employment. In the data, however, employment growth is not persistent while the debt level displays some persistence. This implies that the bargaining channel alone cannot replicate the absence of serial correlation in employment growth together with the persistence in debt level. The addition of separation shocks (stochastic $\lambda_{t}$ ) reduces the autocorrelation in employment growth because it affects the growth of employment without affecting the debt level. This property could be corrected by assuming non-convex hiring costs. Unfortunately, this would also complicate the solution of the model, making the structural estimation impractical (since the numerical solution would be very time consuming).

In the bottom panel of Table 1, we also report the t-statistics for each estimator. The t-statistics provides a guidance to the local identification of parameters. A high t-value means that the target moments are (jointly) statistically sensitive to the parameter. All the parameters are statistically significant at a $1 \%$ confidence interval.

\subsection{The importance of the bargaining channel of debt}

The central question of this paper is whether the bargaining channel of debt is quantitatively important for explaining employment fluctuations at the firm level. To address this question we need to compare the benchmark model with an alternative model in which the bargaining surplus does not depend on the endogenous choice of debt.

The bargaining problem in the benchmark model was defined as

$$
\max _{w_{t}, D_{t}, E_{t}, B_{t+1}} \quad\left[\left(W_{t}\left(B_{t}, N_{t}\right)-U_{t}\right) N_{t}\right]^{\eta} \cdot V_{t}\left(B_{t}, N_{t}\right)^{1-\eta}
$$

where $W_{t}\left(B_{t}, N_{t}\right)-U_{t}$ was the net value for a worker and $V_{t}\left(B_{t}, N_{t}\right)$ the net value for the firm. Recall that the equity value $V_{t}\left(B_{t}, N_{t}\right)$ is linearly decreasing in the debt $B_{t}$. Therefore, higher is the initial debt $B_{t}$ and lower is the value of the firm. This reduces the compensation of workers $w_{t}$ that solves problem (22). 
To isolate this effect, we assume that the net value of the firm also includes the debt $B_{t}$, that is, $V_{t}\left(B_{t}, N_{t}\right)+B_{t}$. The linearity of $V_{t}\left(B_{t}, N_{t}\right)$ to $B_{t}$ implies that the new definition of the net surplus $V_{t}\left(B_{t}, N_{t}\right)+B_{t}$ for the firm does not depend on $B_{t}$. Therefore, the bargained wages will be independent of the initial debt.

This modification, however, also implies that the average net value of the firm is higher compared to the benchmark model (provided that the average value of $B_{t}$ is positive). This also implies that wages are on average higher. To eliminate this effect on average wages, we subtract from the net value of the firm the average debt in the benchmark model.

Denote by $\bar{b}$ the average per-worker debt in the benchmark model. The bargaining problem in this modified problem is

$$
\max _{w_{t}, D_{t}, E_{t}, B_{t+1}} \quad\left[\left(W_{t}\left(B_{t}, N_{t}\right)-U_{t}\right) N_{t}\right]^{\eta} \times\left[V_{t}\left(B_{t}, N_{t}\right)+B_{t}-\bar{b} N_{t}\right]^{1-\eta}
$$

Notice that, if the initial debt is equal to the average debt, that is, $B_{t}=\bar{b} N_{t}$, then we go back to the original problem (22). However, when $B_{t}$ is different from $\bar{b} N_{t}$, the two problems differ. More specifically, a change in $B_{t}$ would affect the wage that solves the original problem (22) but does change the wage that solves the modified problem (23). This is because $V_{t}\left(B_{t}, N_{t}\right)+B_{t}$ is invariant to $B_{t}$.

Appendix $\mathrm{C}$ shows that the first order conditions for the modified model take the form

$$
\begin{aligned}
& \left(q_{t}-\beta\right) b_{t+1}+\beta \eta \bar{b}+\beta(1-\eta) \mathbb{E}_{t}\left[\bar{s}_{t+1}-\varphi_{t+1}\left(b_{t+1}\right)\right]=\Upsilon^{\prime}\left(h_{t}\right), \\
& q_{t} g_{t+1}-\beta \eta h_{t}=\beta\left(g_{t+1}-\eta h_{t}\right)\left(1+\mathbb{E}_{t} \varphi_{t+1}^{\prime}\left(b_{t+1}\right)\right)+\mu_{t} g_{t+1}\left[\beta \xi_{t}\left(1+\mathbb{E}_{t} \varphi_{t+1}^{\prime}\left(b_{t+1}\right)\right)+q_{t}\right] .
\end{aligned}
$$

We can now compare these conditions to the first order conditions that we derived from 
the benchmark model (equations (20) and (21)). For convenience we rewrite them here as

$$
\begin{aligned}
& {\left[q_{t}-\beta(1-\eta)\right] b_{t+1}+\beta(1-\eta) \mathbb{E}_{t}\left[\bar{s}_{t+1}-\varphi_{t+1}\left(b_{t+1}\right)\right]=\Upsilon^{\prime}\left(h_{t}\right)} \\
& q_{t} g_{t+1}=\beta\left(g_{t+1}-\eta h_{t}\right)\left(1+\mathbb{E}_{t} \varphi_{t+1}^{\prime}\left(b_{t+1}\right)\right)+\mu_{t} g_{t+1}\left[\beta \xi_{t}\left(1+\mathbb{E}_{t} \varphi_{t+1}^{\prime}\left(b_{t+1}\right)\right)+q_{t}\right]
\end{aligned}
$$

The comparison of equations (26) and (24) shows that in the benchmark model hiring $h_{t}$ is more sensitive to debt $b_{t+1}$. Therefore, the same change in debt should lead to higher fluctuations in hiring. Notice that the two expressions are identical if $\eta=0$, that is, in the case in which workers have no bargaining power. Comparing (27) to (25) we can see that the left-hand-side of $(25)$ has the extra term $-\eta h_{t}$, which is negative. Therefore, the right-hand-side must also be smaller. This requires a lower value of $b_{t+1}$ and/or a smaller multiplier $\mu_{t}$ if the enforcement constraint binds. Also in this case the first order conditions are identical if $\eta=0$.

Table 3 compares the simulation statistics generated by two versions of the modified model with those obtained by simulating the benchmark model. All the models share the same parameter values (as reported in Table 1). The column labeled Model 1 reports the simulation moments obtained from the model without the bargaining channel of debt. The column labeled Model 2 reports the simulation moments obtained from the model without the bargaining channel of debt and the tax benefit of debt.

The average debt in Model 1 is significantly smaller than in the benchmark model while the level of hiring is slightly higher. This is to be expected given the different first order conditions obtained from the two models as shown above. By eliminating the bargaining channel of debt, firms have lower incentive to borrow since higher debt does not reduce wages but increase the expected cost of financial distress. Still firms continue to borrow because of the tax benefits of debt but the average level is lower. By borrowing less, the expected cost of financial distress is lower and this increases the value of job creation. 
We now turn to the volatility of employment. Model 1 generates a standard deviation of employment growth of 0.100 , compared to 0.106 in the benchmark model. Therefore, the contribution of the bargaining channel of debt to employment fluctuations is about $5.7 \%$ $((0.106-0.100) / 0.106=0.057)$.

In Model 2 we further remove the tax benefits of debt. When simulating the model, we set the corporate tax rate to zero. Since there is neither the bargaining benefit nor the tax benefit, the level of debt becomes undetermined in this model. Since the debt is undetermined, we assume that it is constant at the average level obtained in Model 1. The standard deviation of employment growth in Model 2 decreases only slightly compared to Model 1. Therefore, the contribution of the tax shield to employment fluctuation is negligible. It accounts for only $0.9 \%((0.100-0.099) / 0.106=0.009)$.

\subsection{The role of shocks}

To evaluate the importance of the various shocks, we simulate the benchmark model with only one shock and set the sequences of of the other shocks to their unconditional means. For example, when we simulate the model with the productivity shock only, we set the sequence

of draws for $\xi_{t}$ and $\lambda_{t}$ to their unconditional means, $\bar{\xi}$ and $\bar{\lambda}$. It is important to point out that, even if we set the realizations of the shocks to the unconditional means, this is not anticipated. Firms continue to assume that all shocks follows the process dictated by the estimated parameters. Table 4 reports the simulation results.

With only credit shocks, the model generates a standard deviation of employment growth of 0.013 which is about 12 percent the standard deviation in the benchmark model with all shocks. When we simulate the model with only productivity shocks, the standard deviation of employment growth is 0.077 . Finally, with only separation shocks the model generates a standard deviation of employment growth of 0.071 . The fact that the sum of the standard deviations of each simulation does not sum to 0.106 means that the transmission mechanism of each shock is not independent of other shocks. For example, when productivity is low, the 
impact of a positive credit shock on employment is weaker since firms do not find convenient to hire many workers. As a percentage of the sum of standard deviations generated by each shock individually considered, credit shocks contribute about $8 \%(0.013 /(0.013+0.77+0.71))$, productivity shocks contribute about $48 \%(0.77 /(0.013+0.77+0.71))$, and separation shocks contribute about $44 \%(0.71 /(0.013+0.77+0.71))$. In general, we conclude that credit shocks contribute significantly to employment fluctuations although it is not the main source of firm-level volatility.

Another feature worth emphasizing is that, with only credit (or productivity) shocks, the model generates a much higher autocorrelation of employment. With only separation shocks, instead, the model generates an autocorrelation of employment that is closer to zero. Thus, the addition of separation shocks brings the model closer to the data as emphasized earlier.

\section{Sensitivity analysis}

In this section we re-estimate the model by changing some of the parameters that were not estimated but calibrated. To economize on space, all tables with the sensitivity results are reported in the online appendix, submitted as a separate document.

\subsection{Corporate taxes}

In this section we explore the sensitivity of the results to taxes. Table A.1 in the online appendix reports the simulation results for alternative values of the corporate tax rate: $0 \%$, $10 \%$, and $35 \%$. The benchmark calibration was $20 \%$. All other parameters are set to the same values as in the benchmark model.

The only moment that is sensibly affected by the tax rate is the unused credit ratio. The impact on other moments is negligible. This suggests that the corporate tax rate does not change in important ways the hiring policy of firms.

Next we re-estimate the model after changing the tax rate. Table A.2 reports the estima- 
tion results when the corporate tax rate is set to zero. The model without corporate taxes matches the data quite well. Compared to the benchmark model with $\tau=0.2$, we notice two differences. First, the estimates of the financial distress cost parameter decreases. Second, the workers' bargaining share increases.

The intuition for this change is as follows. Firms trade off the benefits of holding debt (because of tax shield and improved bargaining position with workers) with the financial distress cost. If the tax benefit disappears, in order for the firm to take the same debt, the bargaining channel of holding debt must increase (by raising the bargaining power of workers) or the financial distress cost must fall. This explains why in the estimation without taxes the workers' bargaining share is bigger while the financial distress cost parameter is smaller.

Table A.3 reports the estimation results when the corporate tax rate is set to $35 \%$. As expected, we obtain a higher estimate for the financial distress cost parameter and a lower estimate for the workers' bargaining share.

\subsection{Enforcement parameter}

Table A.4 in the online appendix shows the sensitivity to a different value of the enforcement parameter $\bar{\xi}$. In this case, we calibrate the enforcement parameter $\bar{\xi}$ such that in the steady state the credit-to-sales ratio in the model is equal to the credit-to-sales ratio in the data. In the benchmark estimation we used the credit-to-surplus ratio in the model and the creditto-equity ratio in the data. The value of $\bar{\xi}$ in the benchmark calibration was 0.48 while in the new calibration is 0.39 .

With the new value of $\bar{\xi}$, the ability of the estimated model to match the empirical moments improves slightly. The estimated value of the financial distress parameter increases. A lower value of the enforcement parameter reduces the firm's total credit capacity. This induces the firm to choose a higher utilization of credit. But then, to match the ratio of unused credit observed in the data, the model requires either a higher financial distress cost or a lower bargaining share of workers. 
As a further test of the robustness of the model with respect to the enforcement parameter $\bar{\xi}$, we estimate the value of $\bar{\xi}$ directly from the data. To identify the enforcement parameter, we include an additional moment, the level of financial leverage. Table A.5 reports the results. The estimated value of enforcement parameter is 0.38 , which is close to the alternate calibration value 0.39 in Table A.4.

One noticeable difference between the current estimation and the benchmark estimation is that the estimated hiring cost parameter $\phi$ and the unemployment flow parameter $\bar{u}$ are much smaller. However, both of those two parameters are statistically insignificant at the $10 \%$ confidence interval.

\subsection{Cash holdings}

So far we have used the empirical variable unused lines of credit as a proxy for unused credit capacity. In reality, however, there are many other instruments that allow the firm to maintain financial flexibility and stay away from financial distress (see, for example, Denis and McKeon (2012)). One instrument is cash. Thus, the variable "cash holdings" could contain useful information to identify the financial distress parameter $\kappa$. In this section we re-estimate the model after defining the empirical measure of unused credit as the sum of unused lines of credit and cash holdings.

Table A.6 in the online appendix reports the estimation results. Under the new definition, the unused credit ratio is 0.636 , which is more than $48 \%$ higher than the variable used in the benchmark estimation. The estimate of the financial distress parameter increases dramatically (by 33\%) in order for the model to match the higher unused credit ratio, while the workers' bargaining share parameter decreases (by 10\%).

\subsection{Wage growth}

The model also has implications for the dynamics of wages. Therefore, the use of wage data could improve the estimation of the model. The problem, however, is that we do not have 
access to very detailed data about wages at the firm-level, which explains why we have not included wage data in our benchmark estimation. In this section we re-estimate the model using a proxy for wages: staff expenses (Compustat item XLR) divided by the number of employees.

Since the variable staff expenses is sparsely populated in Compustat, we also use Selling, General \& Administrative Expense (Compustat item XSGA) to measure the total wage payments. Recent studies, e.g., Hulten and Hao (2008), Eisfeldt and Papanikolaou (2013), show that more than $30 \%$ of SG\&A are labor-related expenses. Also, notice that SG\&A includes a broad class of compensation such as stock options and restricted employee equity. Thus, this second proxy of wage also captures the potential conflicts between shareholders and managers (CEOs).

Table A.7 in the online appendix reports the estimation results when we use staff expenses as a proxy for wages. For this estimation, the sample size is largely reduced. We only have 803 year-firm observations in total. Although the model can match the moments quite well, the parameters are not well estimated. Some of the key parameters are not statically significant. Thus, we will focus our discussion on the estimation that uses the second proxy.

Table A.8 reports the estimation results when we use the growth of SG\&A to proxy the growth of wages. Compared to the results of Table A.7, all the parameters are well estimated (statically significant), and the estimated values are quite close to the benchmark estimation of Table 1. The estimation improvement using the second proxy could derive from having a larger sample size and/or a more accurate measurement of total compensation since SG\&A also captures non-cash compensation.

We now turn to the discussion of the wage moments. First, the model matches the standard deviation and the auto-correlation of wage growth. Second, and more importantly, the model simultaneously matches the correlation between wage growth and employment growth, and the correlation between wage growth and credit growth. This suggests that the model can capture the firm's hiring decisions as well as the wage setting policies. 


\subsection{Large vs. small firms}

As a final check, we estimate the model separately for large and small firms. Ex ante, small firms have lower financial leverage, but higher unused credit ratio. One explanation is that small firms have lower borrowing capacity, and they are more financially constrained. Thus, from the estimation, we expect that small firms should face lower enforcement parameter, but higher financial distress cost parameter. Further, we expect small firms to have lower bargaining share of workers, since in practice collective bargaining are more common in large companies.

Tables A.9 and A.10 in the online appendix report the estimation results for large and small firms, respectively. As can be seen from those two tables, the leverage of small firms is significantly lower than that of large firms, but the unused credit ratio is much higher. As expected, the bargaining power parameter is indeed significantly lower for small firms. It is 0.177 for small firms compared to 0.328 for large firms. ${ }^{4}$ We also find that the estimated financial distress parameter is higher for small firms while the enforcement parameter is lower-both of which are consistent with the ex ante conjecture. One divergence from the ex ante conjecture is that the estimated separation rate is higher for large firms. However, the separation parameter $\bar{\lambda}$ is statistically insignificant at $10 \%$ confidence interval in the estimation of small firms.

\section{Reduced-form analysis}

The central mechanism explored in this paper - the impact of debt on hiring through the bargaining channel - is based on the idea that wages are bargained between workers and employers and, when a firm increases its debt, it can negotiate better conditions with workers. In this section we explore further the empirical significance of this channel using reduced-form regressions. We illustrate first that, in the model, the importance of the bargaining channel

\footnotetext{
${ }^{4}$ However, it should be noticed that the bargaining parameter is not statistically significant in the estimation of small firms.
} 
increases with the bargaining power of workers.

Figure 2 plots the response of firm-level employment growth to credit shocks for different levels of the bargaining share of workers $\eta$. The left panel shows that, when the bargaining share is $\eta=0.38$ (estimated value), employment growth increases by $2.3 \%$ in response to a one-standard-deviation positive credit shock. However, if the bargaining share is $\eta=0.46$ (25\% higher than the estimated value), the response of employment growth increases by $3.8 \%$. Therefore, higher is the bargaining power of workers, and higher is the sensitivity employment to firm's debt. ${ }^{5}$ This is the property we would like to test empirically.
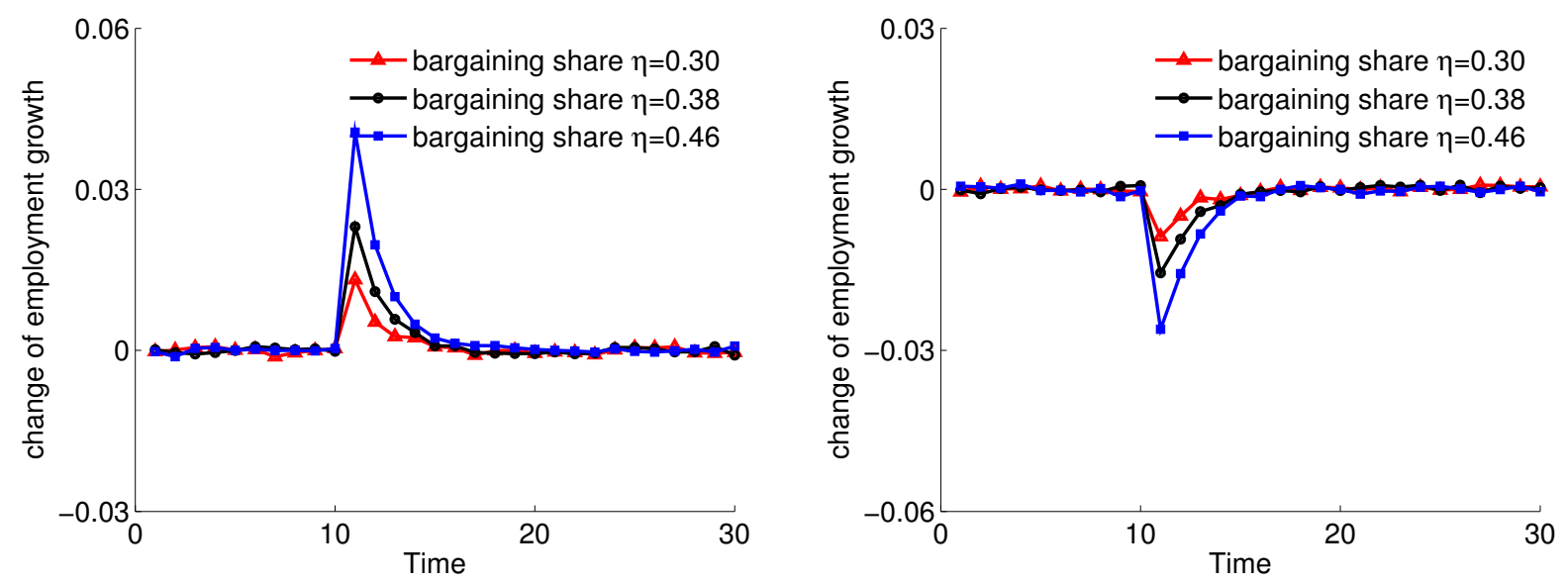

Figure 2: Change in employment growth after credit shocks. The left panel depicts the change in employment growth after a positive credit shock, and the right panel after a negative credit shock.

\subsection{Data description}

In order to test whether the sensitivity of employment to debt depends on the bargaining power of workers, we need a proxy for $\eta$. Following Klasa et al. (2009) and Matsa (2010), we use the unionization index from the Union Membership and Coverage Database. The Union Membership and Coverage Database is maintained by Barry Hirsch and David Macpherson and is publicly available at http://www.unionstats.com. It compiles industry union

\footnotetext{
${ }^{5}$ Similarly, after a one-standard-deviation negative credit shock, the change in employment growth is larger in firms where workers have higher bargaining power. Overall, the impact of negative credit shocks is slightly smaller than that of positive credit shocks.
} 
coverage annually from the Current Population Survey (CPS). We first obtain firm-level employment and balance sheet variables from the COMPUSTAT and Capital IQ. We then merge the variables with the industry unionization rates for the same period 2003-2010. ${ }^{6}$

Ideally, we would like to use the unionization rate for each firm included in the sample. Unfortunately, for the most recent years, which is the focus of this paper, large-sample unionization data is only available at the industry level. ${ }^{7}$ Therefore, we are forced to proxy the bargaining power of workers in a firm with the average unionization index of the industry in which the firm operates. This is also the approach used by Klasa et al. (2009) to study the relation between cash holdings and bargaining power of workers. As a robustness check, we also consider a random sample of 300 firms for which unionization rates have been collected manually for each firm from the SEC 10k filings.

\section{$5.2 \quad$ Regression equation}

The empirical test is based on the following regression:

$$
\begin{aligned}
\text { semploy }_{i t}=\alpha & +\beta_{1} \cdot \text { union }_{\text {cic }, t} \cdot \Delta \text { credit }_{i t}+\beta_{2} \cdot \text { union }_{\text {cic }, t}+\beta_{3} \cdot \Delta \text { credit }_{i t} \\
& +\beta_{4} \cdot \frac{\text { credit }_{i t-1}}{\text { asset }_{i t-1}}+\beta_{5} \cdot \log \left(\text { employ }_{i t-1}\right)+\beta_{6} \cdot Q_{i t} \\
& +\beta_{7} \cdot \frac{\text { asshlow }_{i t}}{\text { asset }_{i t}}+\nu_{i}+\tau_{t}+\varepsilon_{i t} .
\end{aligned}
$$

The dependent variable is employment growth, $\Delta e m p l o y_{i t}$. The main independent variable is the interaction term between industry unionization rate and credit growth, union $_{c i c, t}$. $\Delta$ credit $_{i t}$. The bargaining power of workers is approximated by the unionization rate union $_{c i c, t}$. We control for the lagged credit-to-asset ratio $\frac{\text { credit }_{i t-1}}{\text { asset }_{i t-1}}$ and the lagged log-employment $\log (\text { employ })_{i t-1}$.

\footnotetext{
${ }^{6}$ COMPUSTAT uses the Standard Industrial Classification (SIC), while the Union Membership and Coverage Database uses the CPS Industry Classifications (CIC). We are able to match the SIC code with the CIC code using North American Industry Classification System code (NAICS). After matching the two data sets, we have $162 \mathrm{CIC}$ industries.

${ }^{7}$ One consideration that makes the use of the industry index a good proxy for the bargaining power of workers at the firm level is that labor mobility and competitive pressure tends to be higher within the industry rather than across industries. This implies that, even if a firm do not have unionized workers, it will face higher competitive pressure from other firms if the industry is highly unionized.
} 
Following the investment literature, we also include market-to-book ratio $Q_{i t}$, cash flow-toasset ratio, $\frac{\text { cashflow }_{i t}}{\text { asset }_{i t}}$, firm-level fixed effects, $\nu_{i}$, and year fixed effects, $\tau_{t}$.

Of primary interest is the interaction term between credit growth and unionization rate, union $_{c i c, t} \cdot \Delta$ credit $_{i t}$. We expect that this term has a positive effect on employment growth, that is, $\beta_{1}>0$. This is in addition to the direct effect of credit growth captured by the parameter $\beta_{3}$.

The first column of Table 5 reports the estimation results for the baseline specification of the regression equation (28). The coefficient for the interaction term is 0.088 and it is statistically significant at $1 \%$ level. Therefore, the growth of credit in firms with more unionized labor is associated with higher growth rate of employment.

These results should be taken with caution since we use industry level unionization rates to proxy for the bargaining power of workers employed by an individual firm. Furthermore, in conducting the estimation we are not testing for causality. We are only estimating conditional correlations. Nevertheless, the estimation results are consistent with the predictions of the model.

Turning to the control variables, the first column of Table 5 shows that employment growth is negatively related to lagged employment, and positively related to lagged creditto-asset ratio, market-to-book ratio and cash flow-to-asset ratio.

An alternative way of testing the importance of unionization is by estimating equation (28) without the interaction term, separately for high and low unionization firms. The high unionization group includes firms that operate in industries with higher than median unionization rate. The estimation results are reported in the last two columns of Table 5 . The coefficient of $\Delta$ credit $_{i t}$, is larger for firms with high unionization rates. Thus, the estimation confirms that the relation between employment growth and credit growth increases with the bargaining power of workers, consistent with the theory.

To test the hypothesis that the bargaining channel is more important when firms hire new workers and when they are less likely to be in financial distress, we run the baseline 
regression separately for two different groups of firms: (i) positive and negative employment growth; (ii) large and small firms. Following the literature, we use firm size as a proxy for the status of financial distress based on the idea that large firms are less likely to face financial distress.

Table 6 reports the regression results. As shown in the table, the coefficient of the interaction term union $_{c i c, t} \cdot \Delta$ credit $_{i t}$ is significant only for firms with positive employment growth and for larger firms. These results are consistent with the properties of the model for which the bargaining channel of debt operates when firms hire new workers and when they are not close to a binding borrowing constraint (which in the model implies a higher probability of financial distress).

\subsection{Robustness check}

Table 7 reports the estimation results when we replace the industry-level unionization index with a firm-level index from a random sample of 300 firms. Since firms do not report union information every year in their 10k reports, we are only able to collect one constant unionization rate for each firm, and we make the assumption that firms retain the same unionization rate during the sample period. Thus, any variation in the strength of the relation between employment growth and debt growth would come from the cross-sectional variation in the unionization rate among firms.

Within the 300 randomly sampled firms, 93 firms report that they have at least some collective bargaining coverage. The average unionization rate is 0.08 (which is close to the average of the industry rates) and the standard deviation is 0.17 . Among the 93 firms with non-zero unionization rate, the average rate is 0.26 and the standard deviation is 0.21 .

As can be seen in the first column of Table 7, the coefficient for the interaction term, union $_{i, t} \cdot \Delta$ credit $_{i t}$, is positive and statistically significant at $1 \%$ level. The unionization rate is dropped from the regression because it is constant over the sample period.

The next two columns of Table 7 report the results from the estimation of equation (28) 
without the interaction term but separately for high and low unionization firms. Similar to the results obtained with the industry-level unionization index (Table 5), the estimated coefficient for the variable $\Delta$ credit $t_{i t}$ is larger for the sub-sample of high unionized firms.

\section{Conclusion}

There is a well-established literature in corporate finance exploring the use of debt as a strategic mechanism to improve the bargaining position of firms with workers. Less attention has been devoted to studying whether this mechanism is also important for the hiring decision of firms. In this paper we have investigated the theoretical and empirical relevance of this channel for the employment dynamics of firms.

Using an estimated firm dynamics model, we have shown that this mechanism contributes significantly to employment fluctuations at the level of the firm. We have also shown that the strength of the mechanism increases with the bargaining power of workers. This dependence is also supported by the estimation of reduced-form regressions. Although not explicitly explored in this paper, the bargaining channel could also be important for the long-run dynamics of the firm. In particular, greater uncertainty about the firm's access to credit could have sizable negative effects on its long-run growth. 


\section{References}

Boileau, M. and N. Moyen (2009). Corporate cash savings: Precautionary savings versus liquidity. Unpublished manuscript, University of Colorado, Boulder.

Bronars, S. G. and D. R. Deere (1991). The threat of unionization, the use of debt, and the preservation of shareholder wealth. The Quarterly Journal of Economics 106(1), 231-254.

Dasgupta, S. and K. Sengupta (1993). Sunk investment, bargaining, and choice of capital structure. International Economic Review 34(1), 203-220.

Denis, D. J. and S. B. McKeon (2012). Debt financing and financial flexibility evidence from proactive leverage increases. Review of Financial Studies 25(6), 1897-1929.

Eisfeldt, A. L. and D. Papanikolaou (2013). Organization capital and the cross-section of expected returns. The Journal of Finance 68(4), 1365-1406.

Ellul, A. and M. Pagano (2015). Strategic leverage and employees rights in bankruptcy. Unpublished manuscript, Kelley School of Business, Indiana University and University of Naples Federico II.

Gilchrist, S. and E. Zakrajsek (2012). Bank lending and credit supply shocks. In F. Allen, M. Aoki, N. Kyotaki, R. Gordon, and J. Stiglizt (Eds.), Approaches to the Evolving World Economy. The Proceedings of the 16th World Congress of the International Economic Association. Vol. III: The Global Macro Economy and Finance. Palgrave-MacMillian.

Hennessy, C. and T. Whited (2005). Debt dynamics. Journal of Finance 60(1), 1129-1165.

Hulten, C. and J. Hao (2008). Intangible capital and the market to book value puzzle. Economics Program Working Papers 08-02, The Conference Board.

Ippolito, F. and A. Pérez Orive (2012). Credit lines: The other side of corporate liquidity. Barcelona GSE Working Paper No. 618. 
Jensen, M. C. (1986). Agency cost of free cash flow, corporate finance, and takeovers. American Economic Review 76(2), 323-329.

Jermann, U. and V. Quadrini (2012). Macroeconomic effects of financial shocks. American Economic Review 102(1), 238-71.

Klasa, S., W. F. Maxwell, and H. Ortiz-Molina (2009). The strategic use of corporate cash holdings in collective bargaining with labor unions. Journal of Financial Economics 92(3), $421-442$.

Lee, B.-S. and B. F. Ingram (1991). Simulation estimation of time-series models. Journal of Econometrics 47(2), 197-205.

Li, S., T. M. Whited, and Y. Wu (2014). Collateral, taxes, and leverage. Unpublished manuscript available at SSRN: http://ssrn.com/abstract=2360391.

Matsa, D. A. (2010). Capital structure as a strategic variable: Evidence from collective bargaining. The Journal of Finance 65(3), 1197-1232.

Michaels, R., T. B. Page, and T. M. Whited (2014). Labor and capital dynamics under financing frictions. Unpublished manuscript, University of Rochester.

Modigliani, F. and M. H. Miller (1958). The cost of capital, corporation finance and the theory of investment. The American Economic Review 48(3), 261-297.

Monacelli, T., V. Quadrini, and A. Trigari (2011). Financial markets and unemployment. NBER Working Paper No. 9381.

Perotti, E. C. and K. E. Spier (1993). Capital structure as a bargaining tool: The role of leverage in contract renegotiation. The American Economic Review 83(5), 1131-1141.

Sufi, A. (2009). Bank lines of credit in corporate finance: An empirical analysis. Review of Financial Studies 22(3), 1057-1088. 


\section{A Appendix: Variables definition and sources}

\begin{tabular}{|c|c|c|c|}
\hline Structural estimation & Model & Data & Data Sources \\
\hline $\begin{array}{l}\text { Total Credit } \\
\left(\text { credit }_{i t}\right)\end{array}$ & $\xi_{t} \beta \mathbb{E}_{t} S_{t+1}$ & $\begin{array}{c}\text { Long-Term Debt }{ }_{t} \\
+ \text { Short-Term Debt } \\
+ \text { Total Undrawn Credit } t\end{array}$ & $\begin{array}{c}\text { COMPUSTAT, } \\
\text { Capital IQ }\end{array}$ \\
\hline $\begin{array}{l}\text { Unused Credit Ratio } \\
\left(\text { unused }_{i t}\right)\end{array}$ & $\frac{\xi_{t} \beta \mathbb{E}_{t} S_{t+1}-\beta B_{t+1}}{\xi_{t} \beta \mathbb{E}_{t} S_{t+1}}$ & $\begin{array}{c}\text { Total Undrawn } \text { Credit }_{t} / \\
\text { Total Credit } t_{t}\end{array}$ & $\begin{array}{l}\text { COMPUSTAT, } \\
\text { Capital IQ }\end{array}$ \\
\hline $\begin{array}{l}\text { Credit Growth } \\
\left(\Delta \text { credit }_{i t}\right)\end{array}$ & $\frac{\xi_{t} \beta \mathbb{E}_{t} S_{t+1}}{\xi_{t-1} \beta \mathbb{E}_{t-1} S_{t}}$ & $\begin{array}{l}\text { Total Credit } \\
\text { Total Credit } \\
\text { T-1 }\end{array}$ & $\begin{array}{l}\text { COMPUSTAT, } \\
\text { Capital IQ }\end{array}$ \\
\hline $\begin{array}{l}\text { Employment Growth } \\
\left(\Delta \text { employ }_{i t}\right)\end{array}$ & $\frac{N_{t+1}}{N_{t}}$ & $\begin{array}{l}\text { Employees }_{t} / \\
\text { Employees }_{t-1}\end{array}$ & COMPUSTAT \\
\hline $\begin{array}{l}\text { Sale Growth } \\
\left(\Delta \text { sales }_{i t}\right)\end{array}$ & $\frac{z_{t} N_{t}}{z_{t-1} N_{t-1}}$ & $\begin{array}{l}\text { Sales }_{t} / \\
\text { Sales }_{t-1}\end{array}$ & COMPUSTAT \\
\hline $\begin{array}{l}\text { Wage Growth } \\
\left(\Delta \text { wages }_{t}\right)\end{array}$ & $\frac{W_{t}}{W_{t-1}}$ & $\begin{array}{l}\text { Wages }_{t} / \\
\text { Wages }_{t-1}\end{array}$ & COMPUSTAT \\
\hline $\begin{array}{l}\text { Leverage Ratio } \\
\left(\frac{\text { debt }_{t}}{\text { asset } s_{t}}\right)\end{array}$ & $\frac{B_{t+1}}{(1-\eta) \mathbb{E}_{t} S_{t+1}+B_{t+1}}$ & $\begin{array}{l}\text { Total Debt } \\
\text { Total Assets }\end{array}$ & COMPUSTAT \\
\hline Reduced-form estimation & & Data & Data Sources \\
\hline $\begin{array}{l}\text { Unionization Rate } \\
\left(\text { union }_{c i c, t}\right)\end{array}$ & & $\begin{array}{l}\text { Employees Covered by } \\
\text { Collective Bargaining }_{t} / \\
\text { Total Employees }_{t}\end{array}$ & $\begin{array}{c}\text { Union Membership } \\
\text { and Coverage Database }\end{array}$ \\
\hline $\begin{array}{l}\text { Credit Ratio } \\
\left(\frac{\text { credit }_{i t}}{\text { asset }_{i t}}\right)\end{array}$ & & $\begin{array}{l}\text { Total Credit }_{t} / \\
\text { Total Assets } t\end{array}$ & $\begin{array}{l}\text { COMPUSTAT, } \\
\text { Capital IQ }\end{array}$ \\
\hline $\begin{array}{l}\text { Cash Flow Ratio } \\
\left(\frac{\text { cashflow }}{\text { asset }_{i t}}\right)\end{array}$ & & $\begin{array}{c}\text { Operating Income Before } \\
\text { Depreciation }_{t} / \\
\text { Total Assets }_{t}\end{array}$ & COMPUSTAT \\
\hline $\begin{array}{l}\text { Market to Book Ratio } \\
\left(Q_{i t}\right)\end{array}$ & & $\begin{array}{c}\text { Market Value of Assets } t / \\
\text { Book Value of Assets }\end{array}$ & COMPUSTAT \\
\hline
\end{tabular}




\section{B Simulated method of moments}

We follow Lee and Ingram (1991) in estimating the model. However, one issue to implement their procedure is that the empirical data consists of a panel of heterogenous firms while the artificial data is generated by simulating one firm over a number of periods. To keep consistency between the empirical and simulated data, we demean each variable in the data before calculating the empirical moments.

The estimation procedure consists of the following steps.

1. For each firm $i$ in the data, we calculate the mean of each variable, and then demean the variable using the mean. That is, $\tilde{x}_{i t}=x_{i t}-\bar{x}_{i t}$, where $\bar{x}_{i t}$ is the within-firm average of $x_{i t}$. The subscripts $i$ and $t$ identify, respectively, firm and year. There is one except that we do not demean the data before computing the empirical moment, that is, when we take the mean itself as one of our target moments.

2. We pool the time series of all firms together to form a new time series $\left\{\tilde{x}_{k}\right\}$, where $k=1,2, \ldots, K$, and $K=I * T$ is the total number of firm-year observations.

3. We calculate the empirical moments using the new series $\tilde{x}_{k}$, denote by an $M \mathrm{x} 1$ vector $f\left(x_{k}\right)$, where $M$ is the number of target moments.

4. We then use the model to generate a time series of $S$ periods, denote by $\left\{y_{s}\right\}$. We set $S=10 K$ as suggested by Lee and Ingram (1991). At this point, we also calculate the model moments, denote by vector $f\left(y_{s}, \theta\right)$, where $\theta$ is an $N$ x 1 vector of estimated parameters.

5. The estimator $\widehat{\theta}$ is the solution to

$$
\min _{\theta}[f(x)-f(y, \theta)]^{\prime} \cdot \Omega \cdot[f(x)-f(y, \theta)]
$$

where $f(x)=\frac{1}{K} \sum_{k=1}^{K} f\left(x_{k}\right)$ and $f(y, \theta)=\frac{1}{S} \sum_{s=1}^{S} f\left(y_{s}, \theta\right)$ are the sample mean of the data and the model, respectively, and $\Omega$ is the weighting matrix. 
The $M \times M$ optimal weighting matrix is given by

$$
\Omega=[\widehat{\Sigma}(1+K / S)]^{-1}
$$

where $\widehat{\Sigma}$ is the $M \times M$ variance-covariance matrix defined as ${ }^{8}$

$$
\widehat{\Sigma}=\frac{1}{K} \sum_{k=1}^{K}\left(f\left(x_{k}\right)-f(x)\right)\left(f\left(x_{k}\right)-f(x)\right)^{\prime}
$$

Under mild regularity conditions, the limiting distribution of $\hat{\theta}$ is given by

$$
\sqrt{K}(\hat{\theta}-\theta) \rightarrow N(0, V)
$$

where $V=\left(D W D^{\prime}\right)^{-1}$ and $D^{\prime}$ is the $M \times N$ gradient matrix defined as

$$
D^{\prime}=\frac{\partial f(y, \theta)}{\partial \theta^{\prime}} \approx \frac{f(y, \theta+\Delta \theta)-f(y, \theta-\Delta \theta)}{2 \Delta \theta} .
$$

The t-statistics of the $i$ th estimator is given by

$$
t_{i}=\frac{\hat{\theta}_{i}}{\sqrt{\frac{V_{i i}}{K}}}
$$

\section{Model without the bargaining channel of debt}

As argued in Section 3.4, to isolate the bargaining channel of debt we redefine the value of the firm that enters the bargaining problem as $\widetilde{V}_{t}=V_{t}+B_{t}-\bar{b} N_{t}$. This value can be written recursively as

$$
\widetilde{V}_{t}\left(B_{t}, N_{t}\right)=\widetilde{\Pi}_{t}+\beta \mathbb{E}_{t} \widetilde{V}_{t+1}\left(B_{t+1}, N_{t+1}\right) .
$$

\footnotetext{
${ }^{8}$ As a robustness check, we also calculate the variance-covariance matrix accounting for time-series dependence in the data. However, the impact of time-series dependence is not statistically significant.
} 
where

$$
\widetilde{\Pi}_{t}=\left(z_{t}-w_{t}\right) N_{t}-\Upsilon\left(\frac{H_{t}}{N_{t}}\right)+\left(q_{t}-\beta\right) B_{t+1}-\left(1-\beta g_{t+1}\right) \bar{b} N_{t}-\varphi_{t}\left(\frac{B_{t}}{N_{t}}\right) N_{t}
$$

The recursive formulation is obtained from (4) after adding $\bar{b} N_{t}$ and subtracting $B_{t}$ on both sides of the equation and then using the definition of $\widetilde{V}_{t}=V_{t}+B_{t}-\bar{b} N_{t}$.

The net value for a worker, $W_{t}\left(B_{t}, N_{t}\right)-U_{t}$, is the same as in the benchmark model and takes the form specified in equation (5).

Given $\eta$ the bargaining power of workers, the bargaining problem can be written as

$$
\max _{w_{t}, D_{t}, E_{t}, B_{t+1}} \quad\left[\left(W_{t}\left(B_{t}, N_{t}\right)-U_{t}\right) N_{t}\right]^{\eta} \cdot \widetilde{V}_{t}\left(B_{t}, N_{t}\right)^{1-\eta}
$$

subject to (1), (2) and (3).

Differentiating with respect to $w_{t}$, also in the modified model we obtain that workers receive a fraction $\eta$ of the bargaining surplus $\tilde{S}_{t}\left(B_{t}, N_{t}\right)=\widetilde{V}_{t}\left(B_{t}, N_{t}\right)+\left(W_{t}\left(B_{t}, N_{t}\right)-U_{t}\right) N_{t}$.

Next we derive the optimality conditions for $H_{t}, B_{t+1}$. They maximize the net surplus $\widetilde{S}_{t}\left(B_{t}, N_{t}\right)$ which, in recursive form, can be written as

$$
\widetilde{S}_{t}\left(B_{t}, N_{t}\right)=\max _{H_{t}, B_{t+1}}\left\{\Pi_{t}+\beta\left[1-\eta+\eta(1-\lambda)\left(\frac{N_{t}}{N_{t+1}}\right)\right] \mathbb{E}_{t} \widetilde{S}_{t+1}\left(B_{t+1}, N_{t+1}\right)\right\}
$$

subject to

$$
\begin{aligned}
\Pi_{t}= & \left(z_{t}-u_{t}\right) N_{t}-\Upsilon\left(\frac{H_{t}}{N_{t}}\right)+\left(q_{t}-\beta\right) B_{t+1}-\left(1-\beta g_{t+1}\right) \bar{b} N_{t}-\varphi_{t}\left(\frac{B_{t}}{N_{t}}\right) N_{t} \\
& q_{t} B_{t+1} \leq \xi_{t} \beta \mathbb{E}_{t}\left[\widetilde{S}_{t+1}-B_{t+1}+\bar{b} N_{t+1}\right] .
\end{aligned}
$$

The enforcement constraint remains the same as in the benchmark model, and therefore, it depends on $S_{t}=\tilde{S}_{t}-B_{t}+\bar{b} N_{t}$. 
We can now normalize by $N_{t}$ and rewrite the problem as

$$
\tilde{s}_{t}\left(b_{t}\right)=\max _{h_{t}, b_{t+1}}\left\{\pi_{t}+\beta\left(g_{t+1}-\eta h_{t}\right) \mathbb{E}_{t} \tilde{s}_{t+1}\left(b_{t+1}\right)\right\}
$$

subject to:

$$
\begin{aligned}
& \pi_{t}=z_{t}-u_{t}-\Upsilon\left(h_{t}\right)+g_{t+1}\left(q_{t}-\beta\right) b_{t+1}-\left(1-\beta g_{t+1}\right) \bar{b}-\varphi_{t}\left(b_{t}\right) \\
& \xi_{t} g_{t+1} \beta \mathbb{E}_{t}\left(\tilde{s}_{t+1}\left(b_{t+1}\right)-b_{t+1}+\bar{b}\right) \geq q_{t} g_{t+1} b_{t+1} \\
& g_{t+1}=1-\lambda+h_{t} .
\end{aligned}
$$

The first order conditions for $h_{t}$ and $b_{t+1}$ are

$$
\begin{aligned}
& \left(q_{t}-\beta\right) b_{t+1}+\beta \bar{b}+\beta(1-\eta) \mathbb{E}_{t} \tilde{s}_{t+1}\left(b_{t+1}\right)=\Upsilon^{\prime}\left(h_{t}\right) \\
& g_{t+1}\left(q_{t}-\beta\right)+\beta\left(g_{t+1}-\eta h_{t}\right) \mathbb{E}_{t} \frac{\partial \tilde{s}_{t+1}\left(b_{t+1}\right)}{\partial b_{t+1}}+\mu_{t} g_{t+1}\left[\beta \xi_{t}\left(\mathbb{E}_{t} \frac{\partial \tilde{s}_{t+1}\left(b_{t+1}\right)}{\partial b_{t+1}}-1\right)-q_{t}\right]=0
\end{aligned}
$$

where $\mu_{t}$ is the lagrange multiplier for the enforcement constraint. The envelope condition returns $\partial \tilde{s}_{t}\left(b_{t}\right) / \partial b_{t}=-\varphi_{t}^{\prime}\left(b_{t}\right)$, which allows us to write the surplus function, net of the distress cost, as $\tilde{s}_{t}\left(b_{t}\right)=\bar{s}_{t}-\bar{b}-\varphi_{t}\left(b_{t}\right)$.

\section{C.1 Reformulation of the optimization problem}

We can now use the special form of the surplus function to derive expressions for the maximum collateralizable debt as we did in the benchmark model. First we use the condition that determines the maximum collateralizable debt, that is, $b_{t}^{*}=\xi_{t} s_{t}\left(b_{t}^{*}\right)=\xi_{t}\left[\tilde{s}_{t}\left(b_{t}^{*}\right)-b_{t}^{*}+\bar{b}\right]$. Using (17) to eliminating $\tilde{s}_{t}\left(b_{t}^{*}\right)$, we obtain $b_{t}^{*}=\xi_{t}\left[\bar{s}_{t}-b_{t}^{*}-\varphi_{t}\left(b_{t}^{*}\right)\right]$. Since $\varphi\left(b_{t}^{*}\right)=0$ by definition, we can solve the last equation for $b_{t}^{*}$, that is,

$$
b_{t}^{*}=\left(\frac{\xi_{t}}{1+\xi_{t}}\right) \bar{s}_{t} .
$$


The maximum collateralizable debt is only determined by the exogenous states, $z_{t}$ and $\xi_{t}$. The particular form of the surplus function allows us to write the firm's problem as

$$
\bar{s}_{t}=\max _{h_{t}, b_{t+1}}\left\{z_{t}-u_{t}-\Upsilon\left(h_{t}\right)+g_{t+1}\left(q_{t}-\beta\right) b_{t+1}+\beta g_{t+1} \bar{b}+\beta\left(g_{t+1}-\eta h_{t}\right) \mathbb{E}_{t}\left[\bar{s}_{t+1}-\bar{b}-\varphi_{t+1}\left(b_{t+1}\right)\right]\right\}
$$

subject to:

$$
\begin{aligned}
& \xi_{t} g_{t+1} \beta \mathbb{E}_{t}\left[\bar{s}_{t+1}-b_{t+1}-\varphi_{t+1}\left(b_{t+1}\right)\right] \geq q_{t} g_{t+1} b_{t+1} \\
& g_{t+1}=1-\lambda+h_{t} .
\end{aligned}
$$

The first order conditions can then be rewritten as (24) and (25). 
Figure 3: Workers' bargaining share $\eta$
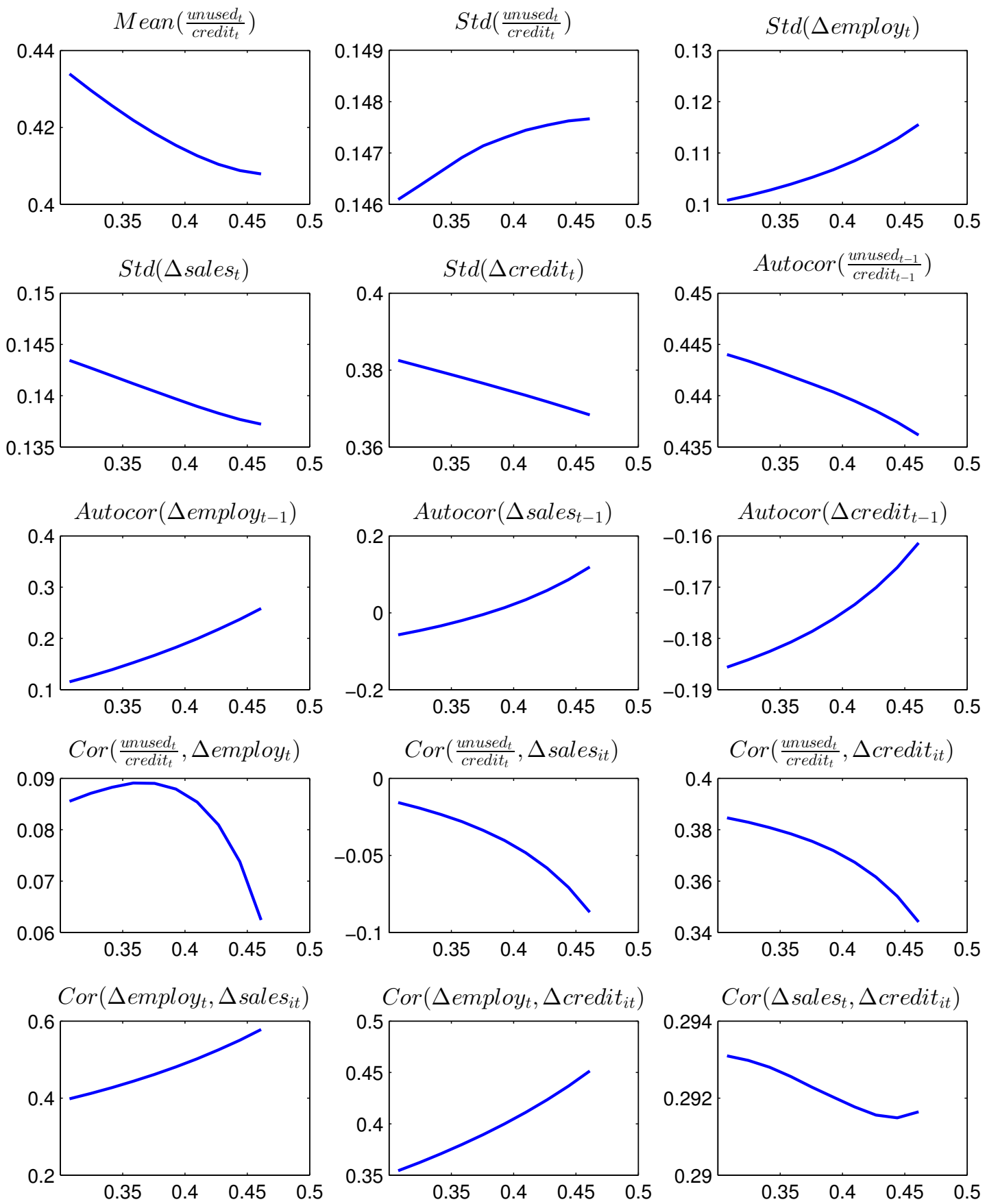

This figure shows each target moment as a function of the workers' bargaining share parameter $\eta$. 
Figure 4: Financial distress cost $\kappa$
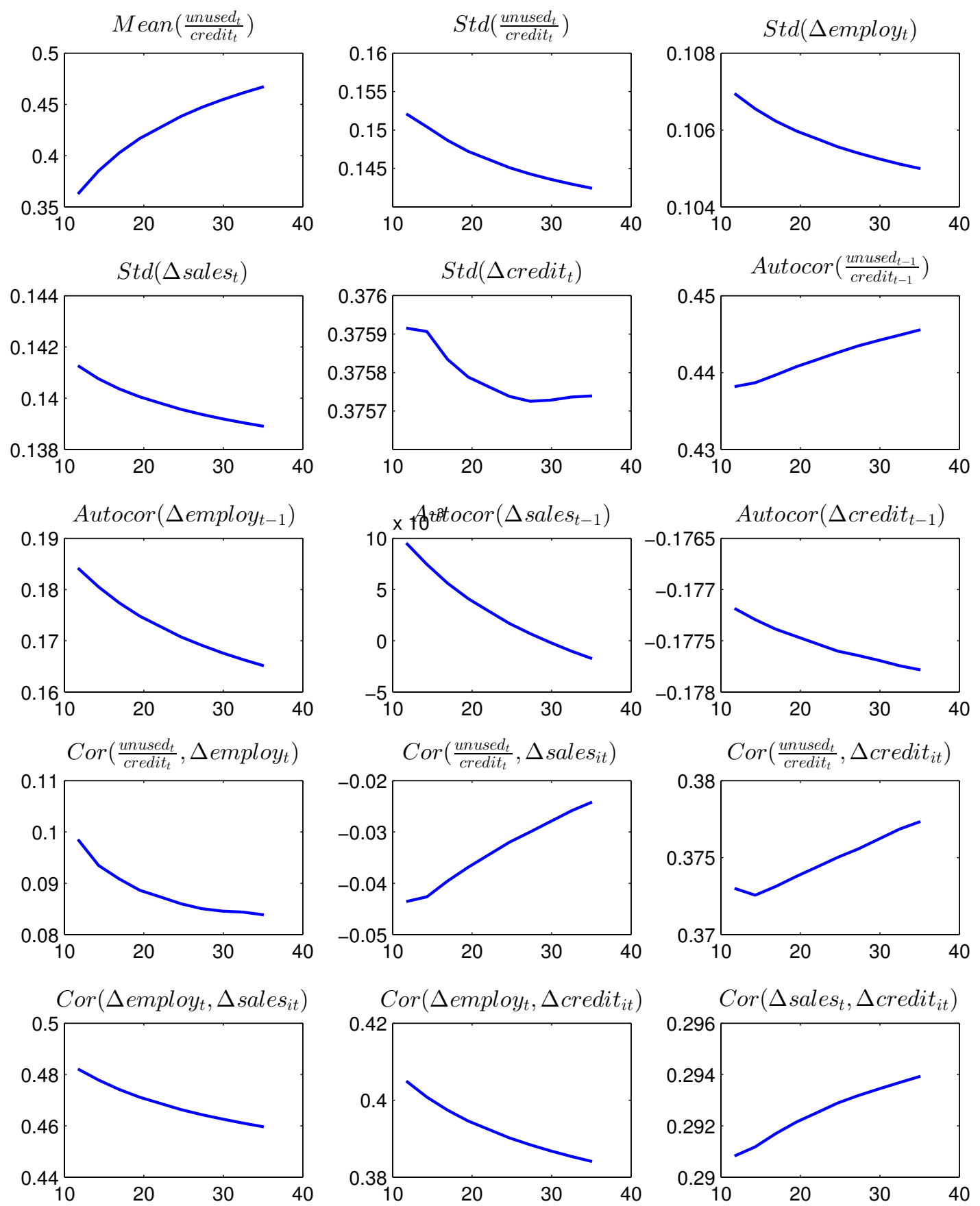

This figure shows each target moment as a function of the financial distress cost parameter $\kappa$. 


\section{Table 1: Structural estimation (benchmark)}

\begin{tabular}{|c|c|c|}
\hline TARGet Moments & Observed & Simulated \\
\hline Mean $\left(\frac{\text { unused }}{\text { credit }_{t}}\right)$ & 0.429 & 0.420 \\
\hline $\operatorname{Std}\left(\frac{\text { unused }_{t}}{\text { credit }_{t}}\right)$ & 0.175 & 0.147 \\
\hline $\operatorname{Std}(\Delta$ employ $)$ & 0.120 & 0.106 \\
\hline $\operatorname{Std}\left(\Delta\right.$ sales $\left._{t}\right)$ & 0.153 & 0.138 \\
\hline $\operatorname{Std}\left(\Delta\right.$ credit $\left._{t}\right)$ & 0.381 & 0.376 \\
\hline Autocor $\left(\frac{\text { unused }_{t-1}}{\text { credit }_{t-1}}\right)$ & 0.322 & 0.440 \\
\hline $\operatorname{Autocor}\left(\Delta\right.$ employt-1 $\left._{t}\right)$ & -0.032 & 0.179 \\
\hline $\operatorname{Autocor}\left(\Delta\right.$ salest-1 $\left._{t}\right)$ & 0.022 & 0.003 \\
\hline $\operatorname{Autocor}\left(\Delta\right.$ credit $\left._{t-1}\right)$ & -0.195 & -0.184 \\
\hline Cor $\left(\frac{\text { unused }_{t}}{\text { credit }_{t}}, \Delta\right.$ employ $\left.y_{t}\right)$ & -0.053 & 0.098 \\
\hline $\operatorname{Cor}\left(\frac{\text { unused }}{\text { credit }_{t}}, \Delta\right.$ sales $\left._{i t}\right)$ & -0.035 & -0.035 \\
\hline $\operatorname{Cor}\left(\frac{\text { unused }_{t}}{\text { credit }_{t}}, \Delta\right.$ credit $\left._{i t}\right)$ & 0.015 & 0.372 \\
\hline $\operatorname{Cor}\left(\Delta\right.$ employ $_{t}, \Delta$ sales $\left._{i t}\right)$ & 0.537 & 0.467 \\
\hline $\operatorname{Cor}\left(\Delta\right.$ employ $_{t}, \Delta$ credit $\left._{i t}\right)$ & 0.288 & 0.403 \\
\hline $\operatorname{Cor}\left(\Delta\right.$ sales $_{t}, \Delta$ credit $\left._{i t}\right)$ & 0.186 & 0.289 \\
\hline Estimated Parameters & Point Estimators & T-Statistics \\
\hline Persistence productivity shock, $\rho_{z}$ & 0.638 & $(18.046)$ \\
\hline Volatility productivity shock, $\sigma_{z}$ & 0.152 & $(27.665)$ \\
\hline Persistence credit shock, $\rho_{\xi}$ & 0.624 & $(34.193)$ \\
\hline Volatility credit shock, $\sigma_{\xi}$ & 0.162 & $(71.042)$ \\
\hline Persistence separation shock, $\rho_{\lambda}$ & -0.328 & $(-4.263)$ \\
\hline Volatility separation shock, $\sigma_{\lambda}$ & 0.101 & $(28.274)$ \\
\hline Financial distress cost, $\kappa$ & 19.501 & $(3.835)$ \\
\hline Workers' bargaining power, $\eta$ & 0.384 & $(5.302)$ \\
\hline Hiring cost, $\phi$ & 0.626 & $(5.181)$ \\
\hline Average separation, $\bar{\lambda}$ & 0.396 & $(9.007)$ \\
\hline Unemployment flow, $\bar{u}$ & 0.453 & $(6.964)$ \\
\hline
\end{tabular}

This table shows the results of the structural estimation. The first panel lists the target moments, and the second panel reports the estimated parameters. 


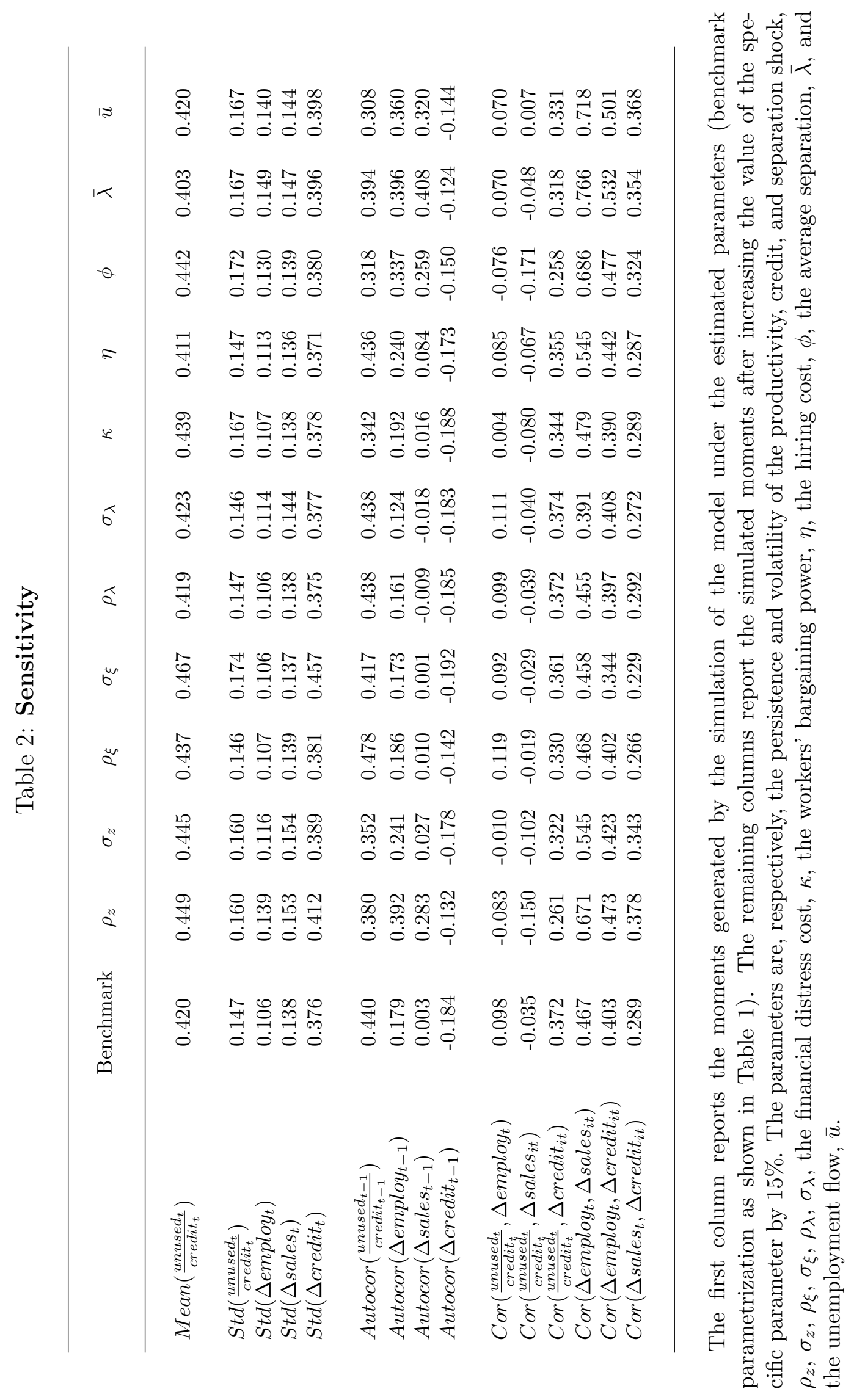


Table 3: The importance of the bargaining channel

\begin{tabular}{|c|c|c|c|c|}
\hline & $\begin{array}{c}\text { Observed } \\
\text { Data }\end{array}$ & $\begin{array}{c}\text { Benchmark } \\
\text { Model }\end{array}$ & $\begin{array}{c}\text { Model } 1 \\
\text { Without } \\
\text { Bargaining }\end{array}$ & $\begin{array}{c}\text { Model } 2 \\
\text { Without Taxes } \\
\text { \& Bargaining }\end{array}$ \\
\hline $\operatorname{Mean}\left(\right.$ hiring $\left._{t}\right)$ & & 0.268 & 0.271 & 0.231 \\
\hline $\operatorname{Mean}\left(\operatorname{debt}_{t+1}\right)$ & & 0.294 & 0.215 & 0.215 \\
\hline Mean $\left(\frac{\text { unused }}{\text { credit }_{t}}\right)$ & 0.429 & 0.420 & 0.588 & 0.560 \\
\hline $\operatorname{Std}\left(\frac{\text { unused }}{\text { credit }}\right)$ & 0.175 & 0.147 & 0.133 & 0.187 \\
\hline $\operatorname{Std}(\Delta$ employt $)$ & 0.120 & 0.106 & 0.100 & 0.099 \\
\hline $\operatorname{Std}\left(\Delta\right.$ sales $\left._{t}\right)$ & 0.153 & 0.138 & 0.142 & 0.137 \\
\hline $\operatorname{Std}\left(\Delta\right.$ credit $\left._{t}\right)$ & 0.381 & 0.376 & 0.389 & 0.391 \\
\hline Autocor $\left(\frac{\text { unused }_{t-1}}{\text { credit }_{t-1}}\right)$ & 0.322 & 0.440 & 0.464 & 0.479 \\
\hline Autocor $\left(\Delta\right.$ employ $\left._{t-1}\right)$ & -0.032 & 0.179 & 0.099 & 0.089 \\
\hline Autocor $\left(\Delta\right.$ sales $\left._{t-1}\right)$ & 0.022 & 0.003 & -0.063 & -0.060 \\
\hline Autocor $\left(\Delta\right.$ credit $\left._{t-1}\right)$ & -0.195 & -0.184 & -0.184 & -0.182 \\
\hline $\operatorname{Cor}\left(\frac{\text { unused }}{\text { creditt }}, \Delta\right.$ employt $)$ & -0.053 & 0.098 & 0.068 & 0.150 \\
\hline $\operatorname{Cor}\left(\frac{\text { unused } t}{\text { credit }_{t}}, \Delta\right.$ sales $\left._{i t}\right)$ & -0.035 & -0.035 & 0.072 & 0.214 \\
\hline Cor $\left(\frac{\text { unused }}{\text { credit }_{t}}, \Delta\right.$ credit $\left._{i t}\right)$ & 0.015 & 0.372 & 0.404 & 0.438 \\
\hline $\operatorname{Cor}\left(\Delta\right.$ employ $_{t}, \Delta$ sales $\left._{i t}\right)$ & 0.537 & 0.467 & 0.380 & 0.365 \\
\hline $\operatorname{Cor}\left(\Delta\right.$ employ $_{t}, \Delta$ credit $\left._{i t}\right)$ & 0.288 & 0.403 & 0.312 & 0.309 \\
\hline $\operatorname{Cor}\left(\Delta\right.$ sales $_{t}, \Delta$ credit $\left._{i t}\right)$ & 0.186 & 0.289 & 0.319 & 0.333 \\
\hline
\end{tabular}

The first column reports the moments of the empirical data, the second column reports the moments of the benchmark model, the third column reports the moments of the modified model without the bargaining channel of debt, and the fourth column reports the moments of the model without the bargaining channel and also without the tax benefits of holding debt. By comparing the simulated moments of the modified model with those generated by the benchmark model we quantify the importance of the bargaining channel of debt for the volatility of firm-level employment. 
Table 4: The contribution of the three shocks

\begin{tabular}{|c|c|c|c|c|c|}
\hline & Observed & $\begin{array}{c}\text { Benchmark } \\
\text { Model }\end{array}$ & $\begin{array}{l}\text { Credit } \\
\text { Shock }\end{array}$ & $\begin{array}{c}\text { Productivity } \\
\text { Shock }\end{array}$ & $\begin{array}{c}\text { Separation } \\
\text { Shock }\end{array}$ \\
\hline Mean $\left(\frac{\text { unused }}{\text { credit }_{t}}\right)$ & 0.429 & 0.420 & 0.427 & 0.487 & 0.490 \\
\hline $\operatorname{Std}\left(\frac{\text { unused }_{t}}{\text { credit }_{t}}\right)$ & 0.175 & 0.147 & 0.142 & 0.015 & 0.014 \\
\hline $\operatorname{Std}\left(\Delta\right.$ employ $\left._{t}\right)$ & 0.120 & 0.106 & 0.013 & 0.077 & 0.071 \\
\hline $\operatorname{Std}\left(\Delta\right.$ sales $\left._{t}\right)$ & 0.153 & 0.138 & 0.013 & 0.117 & 0.071 \\
\hline $\operatorname{Std}\left(\Delta\right.$ credit $\left._{t}\right)$ & 0.381 & 0.376 & 0.329 & 0.135 & 0.059 \\
\hline Autocor $\left(\frac{\text { unused }_{t-1}}{\text { credit }_{t-1}}\right)$ & 0.322 & 0.440 & 0.448 & 0.519 & -0.251 \\
\hline Autocor $\left(\Delta\right.$ employ $\left._{t-1}\right)$ & -0.032 & 0.179 & 0.530 & 0.534 & -0.252 \\
\hline Autocor $\left(\Delta\right.$ sales $\left._{t-1}\right)$ & 0.022 & 0.003 & 0.530 & 0.098 & -0.252 \\
\hline $\operatorname{Autocor}\left(\Delta\right.$ credit $\left._{t-1}\right)$ & -0.195 & -0.184 & -0.230 & 0.022 & -0.078 \\
\hline $\operatorname{Cor}\left(\frac{\text { unused }_{t}}{\text { reditt }_{1}}, \Delta\right.$ employt $)$ & -0.053 & 0.098 & 0.776 & -0.983 & 0.999 \\
\hline $\operatorname{Cor}\left(\frac{\text { unused }}{\text { credit }_{t}}, \Delta\right.$ sales it $)$ & -0.035 & -0.035 & 0.448 & -0.872 & -0.252 \\
\hline $\operatorname{Cor}\left(\frac{\text { unused }_{t}}{\text { credit }_{t}}, \Delta\right.$ credit $\left._{i t}\right)$ & 0.015 & 0.372 & 0.439 & -0.837 & 0.984 \\
\hline $\operatorname{Cor}\left(\Delta\right.$ employ $_{t}, \Delta$ sales $\left._{i t}\right)$ & 0.537 & 0.467 & 0.530 & 0.893 & -0.252 \\
\hline $\operatorname{Cor}\left(\Delta\right.$ employ $_{t}, \Delta$ credit $\left._{i t}\right)$ & 0.288 & 0.403 & 0.384 & 0.854 & 0.984 \\
\hline $\operatorname{Cor}\left(\Delta\right.$ sales $_{t}, \Delta$ credit $\left._{i t}\right)$ & 0.186 & 0.289 & -0.427 & 0.994 & -0.079 \\
\hline
\end{tabular}

The first column reports the moments of the data, and the second column reports the moments of the benchmark model. The last three columns report the moments generated by simulating the model under the estimated parameters (benchmark parametrization as shown in Table 1) but with only one of the three shocks. The simulation with only one shock is obtained by setting the realizations of the other two shocks to their unconditional means. The decision rules, however, are computed under the assumption that firms expect all three shocks to be active. 


\section{Table 5: Employment growth regression. Baseline regression}

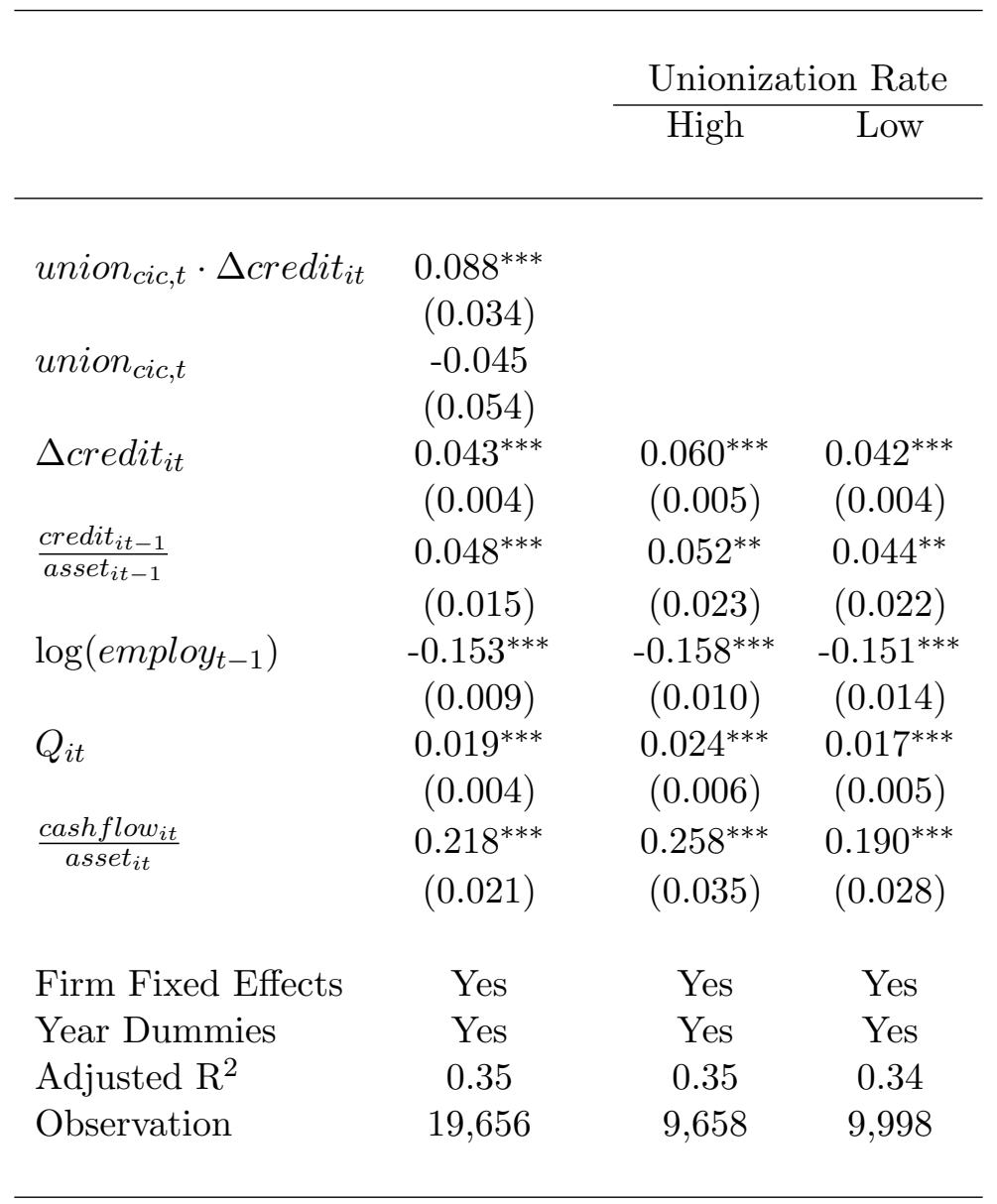

This table reports the regression results using the industry-level unionization data. The first column shows the results of the baseline regression of equation (28). The next two columns report the results of regressions without the interaction term, separately for high and low unionization firms. High unionization firms are those located in industries with higher than median unionization rate. The sample is an unbalanced panel of 3,528 firms during the period 2003 - 2010. The dependent variable is employment growth, $\Delta e^{2}$ ploy $y_{i t}$, and independent variables include: interaction between industry unionization rate and credit growth, union ${ }_{c i c, t} \cdot \Delta$ credit $_{i t}$, industry unionization rate union $_{c i c, t}$, credit growth, $\Delta$ credit $_{i t}$, lagged credit-to-asset ratio, $\frac{\text { credit }_{i t-1}}{\text { asset }_{i t-1}}$, lagged log-employment, $\log (\text { employ })_{i t-1}$, market-to-book ratio, $Q_{i t}$, cash flow-to-asset ratio, $\frac{\text { cashflow }_{i t}}{\text { asset }_{i t}}$. Firm fixed effects and year dummies are also included. Standard errors (in parentheses) are heteroskedasticity robust and clustered at the firm level, and significance levels at 1\%, 5\%, and $10 \%$ are marked with superscripts $^{* * *},{ }^{* *}, *$. 
Table 6: Employment growth regression. Firm grouping

\begin{tabular}{|c|c|c|c|c|c|}
\hline & & \multicolumn{2}{|c|}{ Growth } & \multicolumn{2}{|c|}{ Firm Size } \\
\hline & & Positive & Negative & Large & Small \\
\hline union $_{c i c, t} \cdot \Delta$ credit $_{i t}$ & $\begin{array}{c}0.088^{* * *} \\
(0.034)\end{array}$ & $\begin{array}{c}0.071^{*} \\
(0.038)\end{array}$ & $\begin{array}{c}0.025 \\
(0.022)\end{array}$ & $\begin{array}{l}0.116^{* *} \\
(0.050)\end{array}$ & $\begin{array}{c}0.010 \\
(0.050)\end{array}$ \\
\hline union $_{c i c, t}$ & $\begin{array}{l}-0.045 \\
(0.054)\end{array}$ & $\begin{array}{l}-0.012 \\
(0.069)\end{array}$ & $\begin{array}{c}0.041 \\
(0.043)\end{array}$ & $\begin{array}{l}-0.085 \\
(0.061)\end{array}$ & $\begin{array}{l}-0.068 \\
(0.103)\end{array}$ \\
\hline$\Delta$ credit $_{i t}$ & $\begin{array}{c}0.043^{* * *} \\
(0.004)\end{array}$ & $\begin{array}{c}0.039^{* * *} \\
(0.004)\end{array}$ & $\begin{array}{c}0.004 \\
(0.003)\end{array}$ & $\begin{array}{c}0.060^{* * *} \\
(0.006)\end{array}$ & $\begin{array}{c}0.033^{* * *} \\
(0.005)\end{array}$ \\
\hline$\frac{\text { credit }_{i t-1}}{\text { asset }_{i t-1}}$ & $\begin{array}{c}0.048^{* * *} \\
(0.015)\end{array}$ & $\begin{array}{c}0.068^{* * *} \\
(0.019)\end{array}$ & $\begin{array}{l}-0.018 \\
(0.012)\end{array}$ & $\begin{array}{c}0.093^{* * *} \\
(0.023)\end{array}$ & $\begin{array}{c}0.009 \\
(0.021)\end{array}$ \\
\hline $\log ($ employt-1 $)$ & $\begin{array}{c}-0.153^{* * *} \\
(0.009)\end{array}$ & $\begin{array}{c}-0.134^{* * *} \\
(0.008)\end{array}$ & $\begin{array}{c}-0.050^{* * *} \\
(0.006)\end{array}$ & $\begin{array}{c}-0.166^{* * *} \\
(0.010)\end{array}$ & $\begin{array}{c}-0.161^{* * *} \\
(0.015)\end{array}$ \\
\hline$Q_{i t}$ & $\begin{array}{c}0.019^{* * *} \\
(0.004)\end{array}$ & $\begin{array}{l}0.011^{* *} \\
(0.004)\end{array}$ & $\begin{array}{c}0.003 \\
(0.003)\end{array}$ & $\begin{array}{c}0.013^{*} \\
(0.007)\end{array}$ & $\begin{array}{c}0.024^{* * *} \\
(0.004)\end{array}$ \\
\hline$\frac{\text { cashflow }_{i t}}{\text { asset }_{i t}}$ & $\begin{array}{c}0.218^{* * *} \\
(0.021)\end{array}$ & $\begin{array}{l}-0.042 \\
(0.027)\end{array}$ & $\begin{array}{c}0.121^{* * *} \\
(0.016)\end{array}$ & $\begin{array}{c}0.221^{* * *} \\
(0.050)\end{array}$ & $\begin{array}{c}0.211^{* * *} \\
(0.024)\end{array}$ \\
\hline Firm Fixed Effects & Yes & Yes & Yes & Yes & Yes \\
\hline Year Dummies & Yes & Yes & Yes & Yes & Yes \\
\hline Adjusted $\mathrm{R}^{2}$ & 0.35 & 0.37 & 0.33 & 0.41 & 0.33 \\
\hline Observation & 19,656 & 11,082 & 8,574 & 9,808 & 9,848 \\
\hline
\end{tabular}

This table reports the regression results after sorting firms into positive and negative employment growth group, small and large firm group. Large firms are those with assets larger than the median value. The first column shows the results of the baseline regression of equation (28). The next four columns report the results of regressions, separately for positive and negative employment growth group, small and large firm group. The sample is an unbalanced panel of 3,528 firms during the period 2003 - 2010. The dependent variable is employment growth, $\Delta e m p l o y_{i t}$, and independent variables include: interaction between industry unionization rate and credit growth, union $_{c i c, t} \cdot \Delta$ credit $_{i t}$, industry unionization rate union $_{c i c, t}$, credit growth, $\Delta$ credit $_{i t}$, lagged creditto-asset ratio, $\frac{\text { credit }_{i t-1}}{\text { asset }_{i t-1}}$, lagged log-employment, $\log (\text { employ })_{i t-1}$, market-to-book ratio, $Q_{i t}$, cash flow-to-asset ratio, $\frac{\text { cashflowit }_{i t}}{\text { assetit }_{i t}}$ Firm fixed effects and year dummies are also included. Standard errors (in parentheses) are heteroskedasticity robust and clustered at the firm level, and significance levels at $1 \%, 5 \%$, and $10 \%$ are marked with superscripts ${ }^{* *},{ }^{* *},{ }^{*}$. 


\section{Table 7: Employment growth regression. Firm-level unionization}

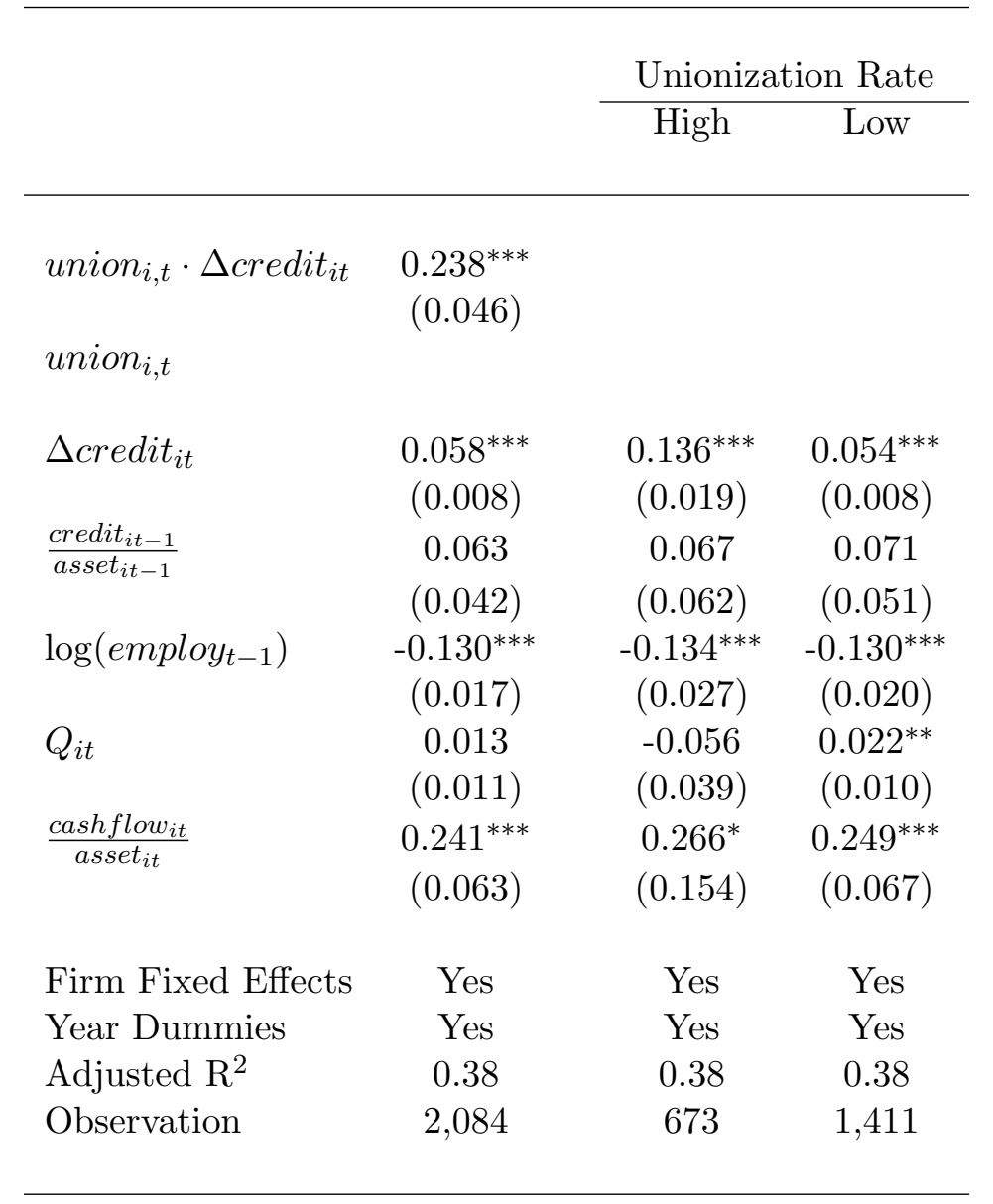

This table reports the regression results using the firm-level unionization data. We randomly sample 300 firms from the unbalanced panel used in the baseline regression and then manually collect the firm-level unionization data from the 10k filings. Within the 300 firms, 93 firms have at least some collective bargaining coverage, and 207 firms do not have any union coverage. High unionization firms are those with higher than median unionization rate (which is zero in this case), and therefore they are also the firms who have at least some collective bargaining coverage. The dependent variable is employment growth, $\Delta e^{2}$ ploy $y_{i t}$, and independent variables include: interaction between industry unionization rate and credit growth, union $c i c, t \cdot \Delta c r e d i t_{i t}$, industry unionization rate union $_{c i c, t}$, credit growth, $\Delta$ credit $_{i t}$, lagged credit-to-asset ratio, $\frac{\text { credit }_{i t-1}}{\text { asset }_{i t-1}}$, lagged log-employment, $\log (\text { employ })_{i t-1}$, market-to-book ratio, $Q_{i t}$, cash flow-to-asset ratio, $\frac{\text { cashflowit }_{i t}}{\text { asset }_{i t}}$. Firm fixed effects and year dummies are also included. Standard errors (in parentheses) are heteroskedasticity robust and clustered at the firm level, and significance levels at 1\%,5\%, and $10 \%$ are marked with superscripts $^{* * *},{ }^{* *}, *$. 